\title{
Massive Hemoptysis: An Update on the Role of Bronchoscopy in Diagnosis and Management
}

\author{
L. Sakr H. Dutau \\ Thoracic Endoscopy Unit, Sainte-Marguerite University Hospital, Marseille, France
}

\section{Key Words}

Hemoptysis - Massive hemoptysis • Bronchoscopy • Endoscopic management • Argon plasma coagulation • Bronchial artery embolization - Electrocautery $\cdot$ Rigid bronchoscopy $\cdot$ Laser photocoagulation

\begin{abstract}
Hemoptysis is frequently encountered in clinical practice, and may be the presenting symptom of a number of diseases. Although massive hemoptysis accounts for only $5-15 \%$ of episodes, it should always be considered as a life-threatening condition that warrants effective assessment and management. In this article, we review the literature with regard to the definition, etiology, epidemiology, pathophysiology, diagnosis and treatment of massive hemoptysis, with special emphasis on the role of bronchoscopy as a diagnostic and therapeutic tool. We briefly present the circumstances under which the use of rigid bronchoscopy should be preferred for controlling massive bleeding. Moreover, we addressthecrucialimportance ofmultidisciplinarycollaboration by illustrating the roles of endovascular therapy and surgery in the optimal management of massive hemoptysis.
\end{abstract}

Copyright $\odot 2010$ S. Karger AG, Basel

\section{Introduction}

Hemoptysis is a frequently encountered symptom in a pulmonologist's practice, with a clinical spectrum ranging from blood-streaked sputum to major bleeding with ensuing respiratory compromise and hemodynamic instability. 'Massive hemoptysis', although accounting for a minority of cases, should always be considered as a lifethreatening condition that requires timely and effective management. Once airway protection and volume resuscitation are ensured, bronchoscopy plays a pivotal role with regard to localization of the anatomic site of bleeding, isolation of the involved airway, control of hemorrhage and treatment of the underlying cause of hemoptysis in case of visible endoluminal lesions. In this article, we will review the definition, etiology, pathophysiology, assessment and management of massive hemoptysis, with special focus on the essential role of bronchoscopy as a diagnostic and therapeutic tool.

\section{Definition}

Although massive hemoptysis is always regarded as a potentially lethal condition, there is no clear consensus on its precise definition. The volume of expectorated

Dr. Hervé Dutau

Thoracic Endoscopy Unit

Hôpital Sainte-Marguerite, 270, Bd de Sainte-Marguerite

FR-13274 Marseille Cedex 09 (France)

Tel. +33 4917446 94, Fax +33 4917454 24, E-Mail herve.dutau@ mail.ap-hm.fr 
blood has often been used to define episodes of massive hemoptysis, but no uniform cutoff value is agreed upon in the literature [1]. Amounts of expectorated blood ranging from $100 \mathrm{ml} / 24 \mathrm{~h}$ to more than $1,000 \mathrm{ml} / 24 \mathrm{~h} \mathrm{[2-19]}$ have been proposed to define massive hemoptysis. Other terms, such as 'major' hemoptysis ( $\geq 200 \mathrm{ml} / 24 \mathrm{~h}$ ) [4, 14], severe hemoptysis ( $\geq 150 \mathrm{ml} / 12 \mathrm{~h}$ in de Gracia et al. [10] and $>400 \mathrm{ml} / 24 \mathrm{~h}$ in Khalil et al. [19]) and 'exsanguinating hemoptysis' [11] ( $\geq 1,000 \mathrm{ml}$ total or $\geq 150 \mathrm{ml} / \mathrm{h}$ ) have also been employed to describe the extent of bleeding. Mal et al. [12] described 'life-threatening' hemoptysis when bleeding occurred at a rate of at least $200 \mathrm{ml} / \mathrm{h}$ in a patient with normal or nearly normal lung function, or at least $50 \mathrm{ml} / \mathrm{h}$ in a patient with chronic respiratory failure, or when more than 2 episodes of moderate hemoptysis (at least $30 \mathrm{ml}$ ) occurred within $24 \mathrm{~h}$ in spite of the administration of intravenous vasopressin. Others have used this term to describe less severe bouts of hemoptysis, with a bleeding rate of $\geq 200 \mathrm{ml} / 24 \mathrm{~h}$ [15], up to $\geq 600 \mathrm{ml} /$ $24 \mathrm{~h}$ [5].

Lack of consensus regarding the cutoff volume, unreliable estimation of expectorated volume and the arbitrary use of this criterion regardless of all the other major determinants of morbidity and mortality, such as the rate of bleeding, the patient's ability to maintain patent airways, and the extent and severity of cardiopulmonary comorbidities, have led to the use of a 'magnitude-of-effect' definition of massive hemoptysis $[1,20]$. This more relevant definition relies on the main clinical consequences of hemoptysis: airway obstruction and hemodynamic instability. Examples of such a definition have included hemoptysis requiring transfusion [6], hospitalization [21], intubation $[13,19]$ or causing aspiration and airway obstruction [11], hypoxemia $\left(\mathrm{PaO}_{2}<8 \mathrm{kPa}\right.$ or $\left.60 \mathrm{~mm} \mathrm{Hg}\right)$ [16] or death [21].

\section{Brief Anatomy Recall}

Massive hemoptysis usually originates from the highpressure bronchial circulation (90\%) [22]. Less frequently, the aorta (aortobronchial fistula, ruptured aortic aneurysm) or nonbronchial systemic circulation (intercostal arteries, coronary arteries, thoracic arteries originating from the axillary and subclavian arteries and the upper and inferior phrenic arteries) may be the source of bleeding (5\%). In a minority of cases, massive hemoptysis may arise from the pulmonary vessels (5\%) [23].

The bronchial arteries originate from the descending aorta, at the level of the $3 \mathrm{rd}-8$ th thoracic vertebral body levels, most often at the T5-T6 level. Wide anatomical variations of the numbers and sites of origin of the bronchial arteries have been described in healthy individuals. The most common pattern (almost $40 \%$ of patients) is a single right bronchial artery with 2 left bronchial arteries arising at the T5-T6 level. About 20\% of bronchial arteries have an aberrant origin from other systemic nonbronchial arteries. In $5 \%$ of patients, a spinal artery originates from a bronchial artery [24].

In chronic inflammatory or infectious lung diseases, many alterations in vascular anatomy may occur. Enlargement and marked tortuosity of bronchial arteries, and increased arterial blood flow have been observed. In addition, vascular anastomoses between bronchial arteries and pulmonary veins, usually present in normal lungs, may become prominent, and new collaterals may develop. These pathological changes can account for an increased risk of bleeding and more complex vascular interventional procedures [25].

\section{Etiology}

The most common causes of massive hemoptysis are listed in table 1. Currently, bronchiectasis, tuberculosis, mycetomas, necrotizing pneumonia and bronchogenic carcinomas are the main underlying conditions $[5,9,12$, $13,15,26,27]$ (table 2). Although tuberculosis accounts for fewer cases of massive hemoptysis in the recent literature $[9,13]$, it remains a frequent etiology in areas with a high prevalence of the disease, such as Africa and China $[5,15]$. In a series of 62 Chinese patients who underwent bronchial arterial embolization for massive hemoptysis ( $\geq 600 \mathrm{ml} / 24 \mathrm{~h}$ ) between 2000 and 2005, the underlying cause was an old tuberculosis in $34(55 \%)$ subjects, bronchiectasis in $14(23 \%)$, mycetoma in $5(8 \%)$, lung cancer in $4(6 \%)$, necrotizing pneumonia in $4(6 \%)$, and an arteriovenous malformation in 1 (2\%) [5]. Knott-Craig et al. [15] found tuberculosis as the underlying disease in $85 \%$ (88/103) of patients who presented with massive hemoptysis in a South African university hospital.

In most other recent studies, however, bronchiectasis accounted for the majority of cases of massive hemoptysis. In a retrospective study from Singapore, where 29 patients were treated for massive hemoptysis in an intensive care unit, bronchiectasis was found in most cases $(n=19$, $66 \%$ ), while mycetoma ( $\mathrm{n}=4,14 \%)$, active tuberculosis $(\mathrm{n}=3,10 \%)$, tumor $(\mathrm{n}=2,7 \%)$ and diffuse alveolar hemorrhage $(\mathrm{n}=1,3 \%)$ were diagnosed in the remaining patients [13]. Similarly, in a recently published French series 
Table 1. Major causes of massive hemoptysis

$\begin{array}{ll}\text { Infectious } & \text { Mycobacteria (particularly tuberculosis) } \\ \text { Fungal infections (including mycetoma) } \\ \text { Necrotizing pneumonia and lung abscess } \\ \text { (Klebsiella pneumoniae, Pseudomonas aeruginosa, } \\ \text { Staphylococcus aureus, Streptococcus pneumoniae, } \\ \text { other Streptococcus spp. and Actinomyces spp.) } \\ \text { Bacterial endocarditis with septic emboli } \\ \text { Parasitic (paragonimiasis, hydatid cyst) }\end{array}$

$\begin{array}{ll}\text { Neoplastic } & \text { Bronchogenic carcinoma } \\ & \text { Endobronchial tumors } \\ & \text { (carcinoid, adenoid cystic carcinoma) } \\ & \text { Pulmonary metastases } \\ & \text { Sarcoma }\end{array}$

Pulmonary Bronchiectasis (including cystic fibrosis) Chronic bronchitis Alveolar hemorrhage and underlying causes

\begin{tabular}{|c|c|}
\hline Vascular & $\begin{array}{l}\text { Pulmonary artery aneurysm } \\
\text { (Rasmussen aneurysm, mycotic, arteritis) } \\
\text { Bronchial artery aneurysm } \\
\text { Pulmonary infarct (embolism) } \\
\text { Pulmonary hypertension } \\
\text { Congenital cardiac or pulmonary vascular } \\
\text { malformations } \\
\text { Airway-vascular fistula } \\
\text { Arteriovenous malformations } \\
\text { Mitral stenosis } \\
\text { Left-ventricular failure }\end{array}$ \\
\hline $\begin{array}{l}\text { Miscella- } \\
\text { neous }\end{array}$ & $\begin{array}{l}\text { Endometriosis } \\
\text { Lymphangioleiomatosis } \\
\text { Broncholithiasis } \\
\text { Cryptogenic } \\
\text { Foreign body aspiration } \\
\text { Lung transplantation }\end{array}$ \\
\hline Vasculitis & $\begin{array}{l}\text { Wegener's granulomatosis } \\
\text { Goodpasture's syndrome } \\
\text { Behçet's disease } \\
\text { Systemic lupus erythematosus }\end{array}$ \\
\hline Trauma & $\begin{array}{l}\text { Induced by diagnostic bronchoscopy } \\
\text { (brushing/biopsy) } \\
\text { Related to interventional pulmonology procedures } \\
\text { (dilation, metallic stent placement, high-dose } \\
\text { brachytherapy) } \\
\text { Catheter-induced PA rupture } \\
\text { Blunt or penetrating chest injury } \\
\text { Transtracheal procedures }\end{array}$ \\
\hline
\end{tabular}

Hemato- Coagulopathy (congenital, acquired or iatrogenic) logical Platelet disorders

$\begin{array}{ll}\text { Drugs and } & \text { Penicillamine } \\ \text { toxins } & \text { Solvents } \\ & \text { Crack cocaine } \\ & \text { Trimellitic anhydride } \\ & \text { Bevacizumab }\end{array}$

of 196 patients admitted to an intensive care unit for severe hemoptysis between January 1999 and December 2001 (median cumulative amount of blood loss averaging $200 \mathrm{ml}$ on admission), bronchiectasis was the leading underlying cause ( $\mathrm{n}=78,40 \%)$, followed by lung cancer $(\mathrm{n}=33,17 \%)$, active tuberculosis $(\mathrm{n}=27,14 \%)$ and mycetoma $(\mathrm{n}=14,7 \%)[26]$.

In a cohort of 57 Austrian patients presenting with life-threatening hemoptysis from January 2000 to January 2004 , lung cancer $(n=20,35 \%)$ was the most common diagnosis, followed by tuberculosis ( $n=13,23 \%$ ), cryptogenic etiology $(n=9,16 \%)$, metastatic disease $(n=6$, $10.5 \%)$, bronchiectasis $(n=5,8.5 \%)$ and vascular malformations ( $\mathrm{n}=4,7 \%)$ [16]. Cystic fibrosis, most often associated with bronchiectasis, has become a more common etiology of massive hemoptysis because of the longer survival of affected patients [6].

Although the bronchial circulation accounts for most cases of massive hemoptysis, pulmonary arteries (PAs) remain the source of bleeding in a substantial number of patients. Massive bleeding may arise from the PA circulation in several pathologic processes, such as necrotizing pulmonary infections (active tuberculosis [23, 28, 29]), pulmonary abscess [23, 28, 29], mycetoma [23, 29]), necrotic cavitary lung carcinoma or Hodgkin lymphoma $[23,28,29]$, vasculitis (Behçet disease or Hughes-Stovin syndrome) $[23,28,30]$, trauma from a PA (Swan-Ganz) catheter [31, 32], and pulmonary arteriovenous malformation [29, 33, 34]. In most patients with infectious or inflammatory etiologies, hemoptysis is due to erosion of small friable PA branches located within the peribronchial tissue. Peripheral PA pseudoaneurysms may also develop in such conditions and become a source of massive bleeding [35]. Other causes of massive PA hemorrhage have included bronchovascular fistulization in the context of lung transplant-related airway anastomotic ischemic or infectious necrosis [36-38], Rasmussen's aneurysms [39, 40], and diagnostic or therapeutic procedure-related bleeding (e.g. transbronchial lung biopsy [41], endobronchial brachytherapy [42] and lung radiofrequency ablation [43]).

Although alveolar hemorrhage is a well-recognized cause of hemoptysis, it rarely presents with massive bleeding since the alveoli can accommodate a large amount of blood. Curiously, despite extensive diagnostic workup, cryptogenic massive hemoptysis has been reported in 11$19 \%$ of cases in the recent literature $[12,26,27,44]$. 
Table 2. Underlying etiology of massive hemoptysis in recent studies

\begin{tabular}{|c|c|c|c|c|c|c|c|c|c|c|}
\hline \multirow[t]{2}{*}{ Study } & \multirow[t]{2}{*}{ Year } & \multirow[t]{2}{*}{ Country } & \multirow{2}{*}{$\begin{array}{l}\text { Patients } \\
\mathrm{n}\end{array}$} & \multicolumn{7}{|c|}{ Underlying cause of hemoptysis, \% } \\
\hline & & & & bronchiectasis & $\mathrm{TB}$ & lung CA & mycetoma & pneumonia & idiopathic & other \\
\hline Shigemura et al. [5] (2009) & $2000-05$ & China & 62 & 23 & 55 & 6 & 8 & 6 & & 2 \\
\hline Valipour et al. [16] (2005) & $2000-04$ & Austria & 57 & 8.5 & 23 & 35 & & & 16 & 17.5 \\
\hline Fartoukh et al. [26] (2007) & $1999-01$ & France & 195 & 40 & 14 & 17 & 7 & 3 & & 9 \\
\hline Ong and Eng [13] (2003) & 1997-01 & Singapore & 29 & 66 & 10 & 7 & 14 & & & 3 \\
\hline Hsiao et al. [52] (2001) & $1988-00$ & USA & 28 & 57 & 7 & 14 & & & 7 & 14 \\
\hline Revel et al. [17] (2002) & 1995-99 & France & 80 & 31 & 19 & 11 & 7.5 & & 10 & 21.5 \\
\hline Mal et al. [12] (1999) & 1985-97 & France & 46 & 9 & 50 & 4 & 2 & 4 & 22 & 9 \\
\hline Knott-Craig et al. [15] (1993) & $1983-90$ & S. Africa & 120 & & 85 & & & & & \\
\hline
\end{tabular}

\section{Epidemiology and Natural History}

Life-threatening massive hemoptysis accounts for only a minority of episodes of hemoptysis, ranging from 5 to $15 \%$ across studies $[1,4,9,16,45]$. In lung cancer patients, hemoptysis occurs in $20 \%$ of subjects at some time during their clinical course, with massive episodes developing as the terminal event in 3\% [46]. In an observational cohort study of the US National Cystic Fibrosis Patient Registry between the years 1990 and 1999, 4.1\% of patients were treated for massive hemoptysis [6].

However, associated mortality is rather high and has been shown to be mainly related to the rate of bleeding. Crocco et al. [7] reported a $71 \%$ mortality rate in patients who lost $\geq 600 \mathrm{ml}$ of blood in $4 \mathrm{~h}$, a mortality rate of $22 \%$ in patients with $\geq 600 \mathrm{ml}$ within $4-16 \mathrm{~h}$, and of $5 \%$ in those with $600 \mathrm{ml}$ of hemoptysis within 16-48 h. When considering patients who lost more than $600 \mathrm{ml}$ of blood within $16 \mathrm{~h}$, mortality rates were shown to exceed $75 \%$ in those deemed inoperable, $78 \%$ in operable patients who were not operated on because of patient refusal or delay in management as compared to $23 \%$ in those who underwent surgical resection. Corey and Hla [4] reported a $58 \%$ mortality rate in patients who lost $\geq 1,000 \mathrm{ml}$ of blood in $24 \mathrm{~h}$ compared to $9 \%$ in those with bleeding rates $<1,000 \mathrm{ml} / 24 \mathrm{~h}$.

In more recent studies, mortality rates for massive hemoptysis have ranged from 9 to $38 \%[9,12,13,15,47]$; the highest (38\%) mortality rate was reported by Hirshberg et al. [9] in a series that included a high proportion of patients with advanced carcinoma [9]. In a most recent single-center study comparing the management of massive hemoptysis ( $\geq 600 \mathrm{ml} / 24 \mathrm{~h})$ and outcomes in a recent 5year period (2000-2005) with those from the previous 5 years (1995-1999), the in-hospital mortality rate was 0\% in the former group compared to $15 \%$ in the latter. A multidisciplinary approach in favor of bronchial artery embolization (BAE) as first-line therapy was the major change in the recent 5-year period. Surgery was undertaken only when BAE failed to stop the bleeding. Old tuberculosis and bronchiectasis were the main underlying diseases in that series [5].

Several studies have tried to establish prognostic features for poor outcome in patients with massive hemoptysis. Bleeding rate of at least $1,000 \mathrm{ml}$ within a 24 -hour period, aspiration of blood in the contralateral lung, massive bleeding requiring single-lung ventilation and bronchogenic carcinoma as an underlying etiology have all been associated with higher mortality $[1,4,8]$. Patients seemed to fare better when tuberculosis, bronchitis or bronchiectasis were responsible for the massive hemoptysis [4]. In a recent study, however, bronchiectasis as an underlying cause was associated with a higher rate of recurrence of hemoptysis in a series of patients treated by BAE [48]. In cancer patients, non-tumor-related hemoptysis was associated with better survival in comparison with tumor-related bleeding, following endovascular management [49]. Van den Heuvel et al. [50] reported higher mortality rates in patients who experienced recurrent bleeding following BAE for massive hemoptysis. In addition, they identified the following risk factors for recurrence of hemoptysis: (1) residual mild bleeding beyond the first week after BAE; (2) blood transfusion before the procedure, and (3) diagnosis of aspergilloma as the underlying etiology. On the other hand, patients with active tuberculosis undergoing medical treatment experienced significantly fewer recurrent bleeding events. Thereafter, the same group prospectively evaluated these risk factors as selection criteria for surgical management following BAE. Low-risk patients ( $\leq 1$ risk factor) were 
not considered surgical candidates, while high-risk subjects (2-4 risk factors) underwent surgery if considered safe according to lung function parameters. No deaths occurred among low-risk or high-risk patients who underwent surgery following embolization. On the other hand, 2/7 high-risk subjects who were deemed inoperable died during follow-up [51].

\section{Diagnosis}

Diagnostic workup for massive hemoptysis should be undertaken as soon as airway protection and hemodynamic status are assessed and stabilized. If possible, a careful history and clinical examination should be performed in order to rule out nonpulmonary causes of bleeding such as epistaxis and hematemesis.

There is no consensus on the optimal diagnostic approach to massive hemoptysis. However, several studies have explored the clinical utility of performing a chest radiograph, a computed tomography (CT) scan and bronchoscopy before definitive treatment strategies. Chest radiography can identify the site of bleeding in $33-82 \%$ of cases of massive hemoptysis $[9,13,17,19,52,53]$, and may reveal the underlying cause in 35\% [19], most of which including either tuberculosis or tumors. Although chest radiographs are rarely normal in episodes of massive hemoptysis, normal findings have been shown to suggest bronchiectasis as the cause of bleeding $[19,52]$.

CT might be superior to chest radiography, and comparable to bronchoscopy for detecting the site of bleeding in massive hemoptysis, with correct localization in 70$88.5 \%$ of cases $[17,19,53]$. In addition, CT is much more efficient than bronchoscopy for determining the cause of bleeding ( $60-77$ vs. $2.5-8 \%$ ) [17, 19]; this has already been demonstrated in earlier studies $[27,54,55]$. Moreover, by showing possible extrapulmonary causes of hemoptysis, such as false aortic aneurysms [19], CT can obviate the need for bronchial arteriography. While some authors suggest that CT can replace bronchoscopy as a first-line investigational approach in patients with large $(<300$ $\mathrm{ml} / 24 \mathrm{~h}$ ) or massive hemoptysis ( $>300 \mathrm{ml} / 24 \mathrm{~h}$ ) because of its higher diagnostic yield [19], others advocate it as complementary to fiber-optic bronchoscopy (FOB) for bleeding site identification [17]. Hsiao et al. [52] showed that radiographic studies (chest radiography and CT) are highly informative to guide the approach to bronchial artery embolization, and therefore obviate the need for FOB in patients with hemoptysis of known etiology, not requiring airway management. In addition, high-resolu- tion CT scans might provide prognostic information since a correlation has been found between the extent of lobar involvement on high-resolution CT and the daily and cumulative amount of bleeding [17]. Recently, multidetector CT has been proven valuable for a precise delineation of bronchial and nonbronchial systemic arteries. Yoon et al. [56] were able to identify all 31 bronchial arteries and 16 of 26 (62\%) nonbronchial systemic arteries causing hemoptysis, using a 16 -detector row CT. Interestingly, they were also able to trace $(23 / 31,75 \%)$ most of the bronchial arteries causing bleeding from their origin to the hilum while only 1 of 9 (11\%) bronchial arteries not causing hemoptysis was traceable. In a study by RemyJardin et al. [57], multidetector CT allowed more accurate identification of bronchial and nonbronchial systemic arteries in comparison with conventional angiography. CT features consistent with nonbronchial systemic arterial supply were (1) pleural thickness of $\geq 3 \mathrm{~mm}$ near a parenchymal opacity, and (2) enhancing vessels within the extrapleural fat layer [58]. Moreover, in a recent study, multidetector CT was proven effective for accurate identification and early management of massive hemoptysis of PA origin [23]. Signs of PA bleeding consisted of the following: (1) PA pseudoaneurysm, or (2) aneurysm, or the presence of a PA in the inner wall of a cavitary lesion. In addition, multidetector CT findings of associated bronchial arterial hypertrophy predicted the need for simultaneous bronchial artery and PA embolization [23].

Despite these important advantages specific to CT, this imaging technique has several limitations. Indeed, in unstable patients, in patients with active bleeding requiring endobronchial management, and in patients with bilateral lung abnormalities in whom radiographic bleeding localization might be challenging, FOB appears to be the optimal approach prior to definitive endovascular treatment.

FOB identifies the site of bleeding in $73-93 \%$ of episodes of massive bleeding [17, 19, 52]. Its diagnostic yield for bleeding localization has been shown to be significantly lower in cases of mild or moderate hemoptysis [27, 55]. The optimal timing for a diagnostic FOB in hemoptysis remains a controversial issue $[1,59]$. Although the likelihood of visualizing the site of bleeding was significantly better with early versus delayed FOB, the timing of the procedure did not alter therapeutic decisions or clinical outcome in nonmassive hemoptysis [1, 59-61]. It is crucial, however, to recognize the limitations of FOB in massive, life-threatening hemoptysis. Interventional pulmonologists should not rely on flexible bronchoscopes in such situations, as this will delay timely and effective 
management. Rigid bronchoscopy is more efficient at safeguarding airway patency, preserving ventilation, and allowing better clearance of the airways, therefore improving visualization [18]. However, a flexible fiber-optic bronchoscope can be introduced through the rigid scope as it provides easier access to the upper lobes and peripheral bronchi, thus allowing optimal exploration of the bronchial tree [62].

\section{Management of Massive Hemoptysis}

The initial approach for management of massive hemoptysis involves protection of the airways and volume resuscitation $[1,62]$. If the bleeding side is known, the patient should be placed in a lateral decubitus position, with the bleeding side down in order to prevent aspiration into the unaffected lung (fig. 1). The patient should be transferred to an intensive care unit where careful monitoring and effective management can be provided. If hemodynamic or respiratory status is compromised, urgent rigid bronchoscopy should be attempted by a skilled physician, as it is the most efficient means of clearing the airways from blood clots and secretions, ensuring effective tamponade of the bleeding airway and safe isolation of the nonaffected lung, thereby preventing asphyxia and preserving ventilation.

However, not all bronchoscopists are trained in rigid bronchoscopy. Moreover, a bronchoscopist is not always readily available in the event of massive hemoptysis. In such circumstances, the patient should be intubated with a large-caliber endotracheal tube (preferably size 8 or more), and FOB should be immediately performed, mainly to suction blood clots and secretions. Alternatively, once the airways are cleared, unilateral intubation can be performed to protect the nonbleeding lung from aspiration and to allow effective ventilation while awaiting definitive treatment strategies. However, it is not advisable to selectively intubate the right main bronchus in case of bleeding originating from the left lung as this procedure would occlude the right upper lobe bronchus, further compromising gas exchange. Instead, tracheal intubation can be performed, followed by insertion of a balloon catheter besides the endotracheal tube through the vocal cords, with subsequent introduction into the left main bronchus under bronchoscopic visualization. Although double-lumen intubation also allows isolation of the bleeding lung while preventing aspiration into the unaffected lung, this procedure requires highly trained medical personnel, and should only be performed after clear-

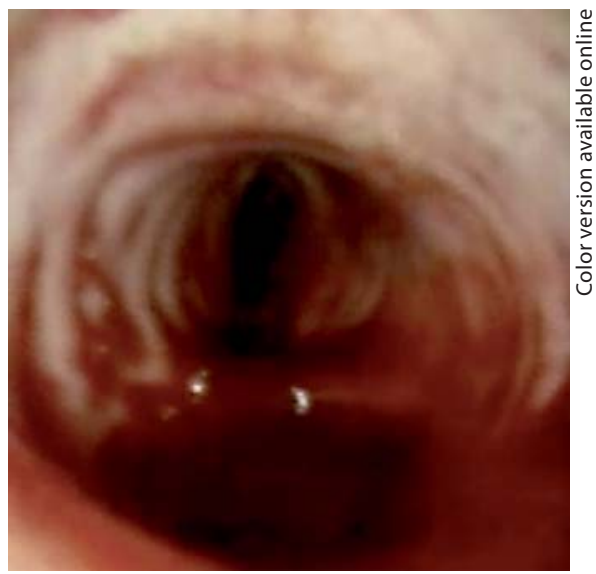

Fig. 1. Left lateral decubitus position in a patient with massive hemoptysis originating from the left bronchial tree. This position prevents flooding of the contralateral unaffected lung.

ing the airways. Once hemodynamic and respiratory conditions are stabilized, urgent endovascular therapy should be considered.

\section{Bronchoscopic Treatment}

When expertise is available, bronchoscopic treatment strategies ensure adequate control of bleeding, therefore contributing to stabilization of the patient's hemodynamic status and respiratory parameters. They are most often temporary measures for early management; however, in some circumstances, bronchoscopic management provides a long-lasting hemostatic effect.

First, a skilled bronchoscopist should be aware of basic strategies to manage procedure-induced bleeding in the endoscopy suite. Such strategies include performing biopsies in dependent areas of the lung, whenever possible, so as to facilitate bleeding control. Following a transbronchial biopsy, the bronchoscope should be kept in a wedged position, in order to ensure effective tamponade of the bleeding mucosa. Suctioning and frequent scope repositioning should be kept to a minimum between sampling to avoid dislodging freshly formed blood clots. Once all desired biopsies are performed, wedging should be maintained for 3-5 min, following which the bronchoscope is withdrawn carefully and gradually, and suction is applied only at a certain distance from the biopsy site. If vision is obscured during the procedure, the bronchoscope can be gently rubbed against tracheal cartilage and/or cold saline may be applied locally [63]. If massive bleed- 
ing is encountered, more aggressive interventional strategies should be attempted, as outlined below.

Rigid bronchoscopy clearly has merits with regard to airway assessment and management in patients with massive life-threatening hemoptysis. It is very efficient at securing airway patency and safeguarding ventilation, thereby preventing asphyxia. It allows better suction of blood clots and secretions through its large working channel, and improved visualization of the airways. It also provides effective tamponade of accessible bleeding sites, and allows isolation of the nonaffected lung. In addition, bronchial blocking using a variety of endoscopic devices - as described in detail below - is much easier to perform through the wider lumen of a rigid bronchoscope. The latter therefore allows stabilizing a patient's hemodynamic and respiratory conditions before proceeding with further diagnostic or therapeutic interventions. If the underlying lesion is endoluminal, whether in the central airways or in more peripheral bronchi within the reach of the rigid scope, the latter allows further management, including local coagulation therapy (laser, electrocautery, argon plasma coagulation, APC), as outlined below. Therefore, rigid bronchoscopy is safer and much more efficient than its flexible counterpart at controlling hemoptysis in patients with compromised airways. However, FOB might be useful as a complementary tool for optimal inspection of the upper lobes and peripheral airways.

Whether a rigid bronchoscope should be available in every bronchoscopy suite remains a controversial issue. More importantly, the main question is whether training in rigid bronchoscopy should be offered on a larger scale, an example of which would consist of introducing such technical skills into respiratory fellowship programs. A recent survey conducted among US respiratory/critical care fellowship directors revealed that the presence of an interventional pulmonologist on staff was associated with increased availability of advanced procedural training, including rigid bronchoscopy-related skills, However, only $41 \%$ of the training programs which offered rigid bronchoscopy procedures allowed fellows to reach the targeted number (20 procedures) to obtain competency [64]. Another survey conducted among Canadian respirologists in 2002 showed that only $20.8 \%$ of specialists performed rigid bronchoscopy [65]. Training in rigid bronchoscopy requires availability of a proficient interventional pulmonologist in the service as well as performance of a sufficient amount of procedures in order to develop the required skills. In addition, following the training period, regular performance of rigid bronchos- copy is required in order to maintain and improve such skills, especially when using rigid bronchoscopy in urgent settings such as management of massive hemoptysis. Availability of an operating theater, an anesthesiologist and good and effective collaboration with thoracic surgeons are necessary as well. Such requirements are difficult to meet in most hospital centers; therefore, not all bronchoscopists need to train and become proficient in rigid bronchoscopy.

In the following discussion, we present an overview of the various bronchoscopic devices and treatment strategies used in clinical practice (table 3). Again, we would like to emphasize that, although some of the following procedures can be performed by FOB, rigid bronchoscopy is more efficient and much safer in the hands of welltrained personnel.

\section{Cold-Saline Lavage}

The first case of endobronchial irrigation with cold saline for the early management of hemoptysis was reported in 1980 [18]. Lavage with normal saline at $4{ }^{\circ} \mathrm{C}$ in $50-\mathrm{ml}$ aliquots (average volume of $500 \mathrm{ml}$, range $300-750$ $\mathrm{ml}$ ) stopped the bleeding in 23 patients with massive hemoptysis ( $\geq 600 \mathrm{ml} / 24 \mathrm{~h}$ ), obviating the need for emergency thoracotomy. A rigid bronchoscope was used during the session, and was introduced in an alternate manner on the nonbleeding side in order to isolate the lung and enable gas exchanges, and subsequently on the bleeding side to evacuate clots and large amounts of blood, and to perform local irrigation. One patient experienced transient sinus bradycardia during the procedure. Only 2 subjects suffered subsequent episodes of massive bleeding 3 and 10 days later, and required further lavage. All patients underwent subsequent medical or surgical therapy after stabilization, and all were discharged free of hemoptysis $[18,66]$.

Although cold-saline irrigation is also feasible with a FOB, the rigid scope has better suction capacity, thus enabling a better view of the involved area.

\section{Topical Vasoconstrictive Agents}

Local instillation of topical vasoconstrictive agents in the bleeding airway can be effective in mild to moderate hemoptysis following bronchial brushing and biopsy procedures [67-69]. This approach is not useful for massive bleeding, however, because the drug is diluted and washed away [70]. Interestingly, in a recent study evaluating hemostatic tamponade therapy for the management of massive hemoptysis, 13 of 76 (17\%) patients were excluded because of prior response to conservative therapy consisting of 
topical epinephrine $(1: 20,000)$ and/or cold-saline lavage, therefore obviating the need for further tamponade [16].

However, some studies have reported high plasma levels following endobronchial application of epinephrine [71], with significant cardiovascular effects namely acute hypertension and tachyarrythmias [72]. This observation prompted some investigators to use topical antidiuretic hormone derivatives, such as terlipressin and ornipressin, for their vasoconstrictive effect. Topical ornipressin proved as effective as adrenaline at promoting hemostasis but with significantly fewer hemodynamic adverse events [73]. In a trial comparing intravenous and endobronchial administration of terlipressin during bronchoscopy-induced bleeding, a similar hemostatic effect was observed for both routes; however, drug plasma levels were 251-fold higher and diastolic pressure was significantly increased following intravenous administration [67].

\section{Tranexamic Acid}

This antifibrinolytic drug administered via the oral or intravenous route is widely used for the treatment or prophylaxis of mucosal bleeding in patients with bleeding disorders or following major surgery [74]. Several case reports documenting its efficacy in controlling major hemoptysis in cystic fibrosis patients have recently been published. Wong et al. [75] reported successful management of recurrent hemoptysis with intravenous followed by oral tranexamic acid (TA) in a patient with cystic fibrosis and collateral vessels after repeated failure of BAE. Chang et al. [76] described a cystic fibrosis patient with recurrent episodes of major hemoptysis caused by multiple aberrant bronchial arteries. Repeated BAEs were only partially successful. TA was eventually started and controlled bleeding effectively for 5 months, until a recurrent episode prompted surgical resection. Graff [77] reported another successful trial of oral TA treatment in a cystic fibrosis patient after 12 previous BAE procedures had failed to control relapse of hemoptysis. Further BAE was counter-indicated because of bronchial to spinal artery collaterals. Several attempts to stop TA were followed by recurrence of bleeding. The patient was therefore maintained on TA therapy for 13 months without adverse events.

Topical use of TA has also proven effective for several other indications. TA mouthwash has successfully controlled bleeding following oral surgery in anticoagulated patients $[78,79]$. Intrapleural administration of TA in combination with the oral preparation has effectively reduced bleeding and transfusion requirements in patients with malignant mesothelioma presenting with hemotho$\operatorname{rax}[80]$.

Massive Hemoptysis: Bronchoscopy in Diagnosis and Management
Topical administration of TA within the bronchial tree has been described only recently. Two patients experienced severe bleeding from malignant tumors following bronchoscopy. Bronchoscopic procedures consisted of transbronchial biopsy in one patient and electrocautery treatment of a visible endoluminal lesion in the other. Ensuing bleeding, which ranged from $600-750 \mathrm{ml}$, did not respond to initial conservative therapy (cold saline, epinephrine) but was successfully managed thereafter with endobronchial instillation of TA (500-1,000 mg). Bleeding stopped within seconds of application, and patients were discharged within a few days without recurrence of hemoptysis [81].

\section{Fibrinogen/Thrombin}

Endoscopic instillation of fibrinogen-thrombin combination in a series of 11 patients with severe hemoptysis ( $\geq 150 \mathrm{ml} / 12 \mathrm{~h}$ ), in whom BAE was [75] contraindicated, unavailable or ineffective, has been described recently [10]. After local application of cold saline, epinephrine, or collapse of the bleeding bronchus through continuous suction, and drying of the airway thereafter with oxygen, the fibrinogen-thrombin combination was instilled through a catheter within an FOB. In addition, factor XIII and aprotinin were added to the mixture for better stabilization of the fibrin clot. This approach allowed immediate arrest of bleeding in all patients. Early recurrence of severe hemoptysis occurred in 2 patients, $6 \mathrm{~h}$ and 3 days after treatment, respectively, whereas late relapse occurred in 1 patient 12 months after the procedure.

In a previous study by Tsukamoto et al. [82], immediate control of massive bleeding was achieved in 6 of 10 patients treated with thrombin, and in all 9 patients managed with a fibrinogen-thrombin mixture. Short-term relapse of hemoptysis in the fibrinogen-thrombin group occurred in 3 patients, between $24 \mathrm{~h}$ and 14 days following the procedure. Bense [83] also reported 3 patients successfully treated with the fibrinogen-thrombin combination for hemoptysis, with 1 short-term relapse.

This approach seems promising as an initial strategy for the early management of massive hemoptysis while awaiting BAE, or as an alternative treatment when endovascular procedures cannot be performed for the reasons stated above. However, further clinical studies are needed before endorsing this treatment in massive hemoptysis.

\section{Balloon Tamponade}

The successful use of a Fogarty balloon catheter for endobronchial tamponade in life-threatening hemoptysis was initially described in 1974 [84, 85]. It was inserted 
Table 3. Bronchoscopic treatment strategies for massive hemoptysis

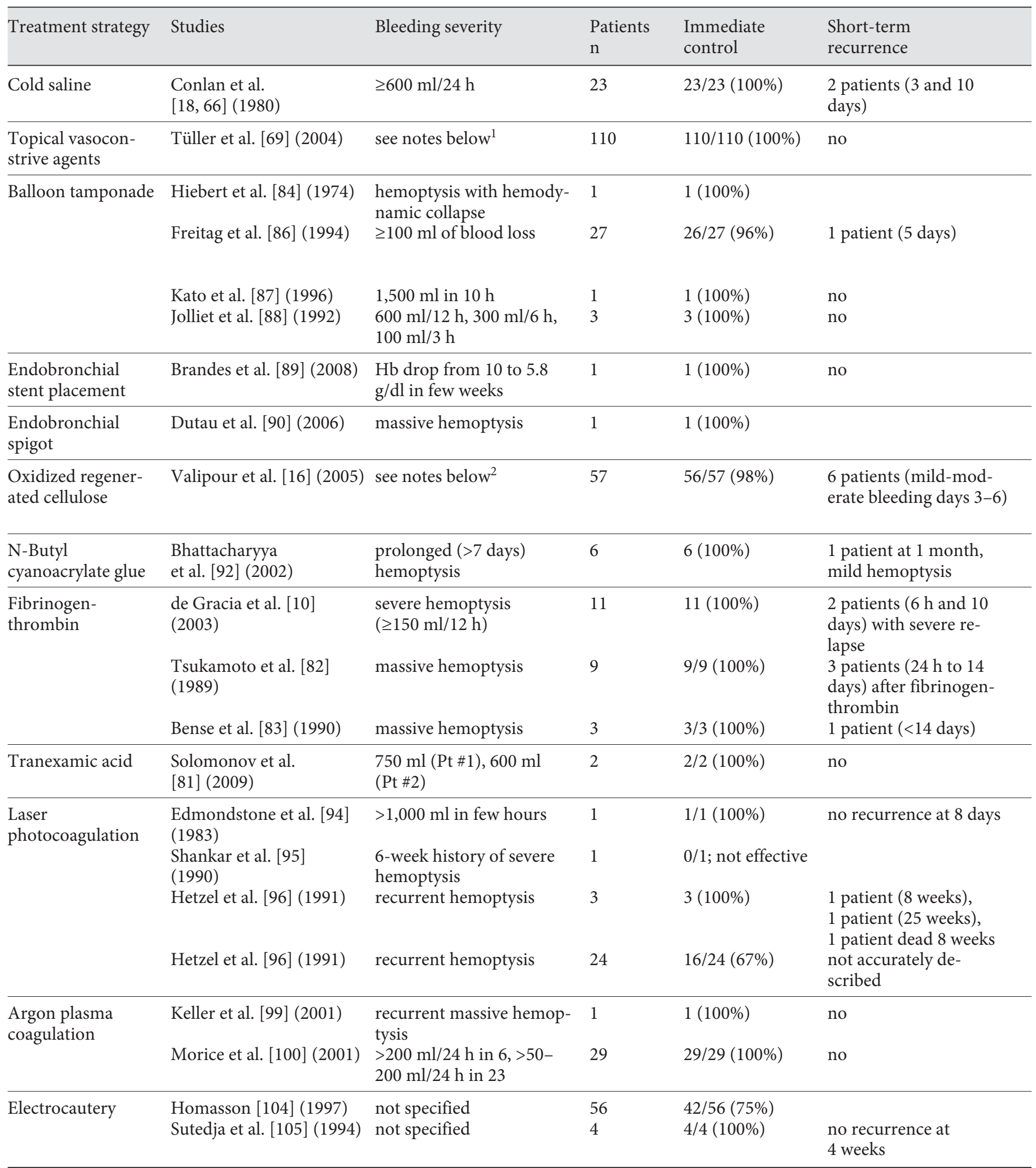

\footnotetext{
${ }^{1}$ Bleeding persisting for 2 min of continuous suction, bleeding increasing in time or considered as major.

${ }^{2}>150 \mathrm{ml} / \mathrm{h}$, or $\geq 150 \mathrm{ml}$ on one occasion, plus clinical consequences such as impaired respiratory function with a $\mathrm{PaO}_{2}<60 \mathrm{~mm} \mathrm{Hg}$.
} 


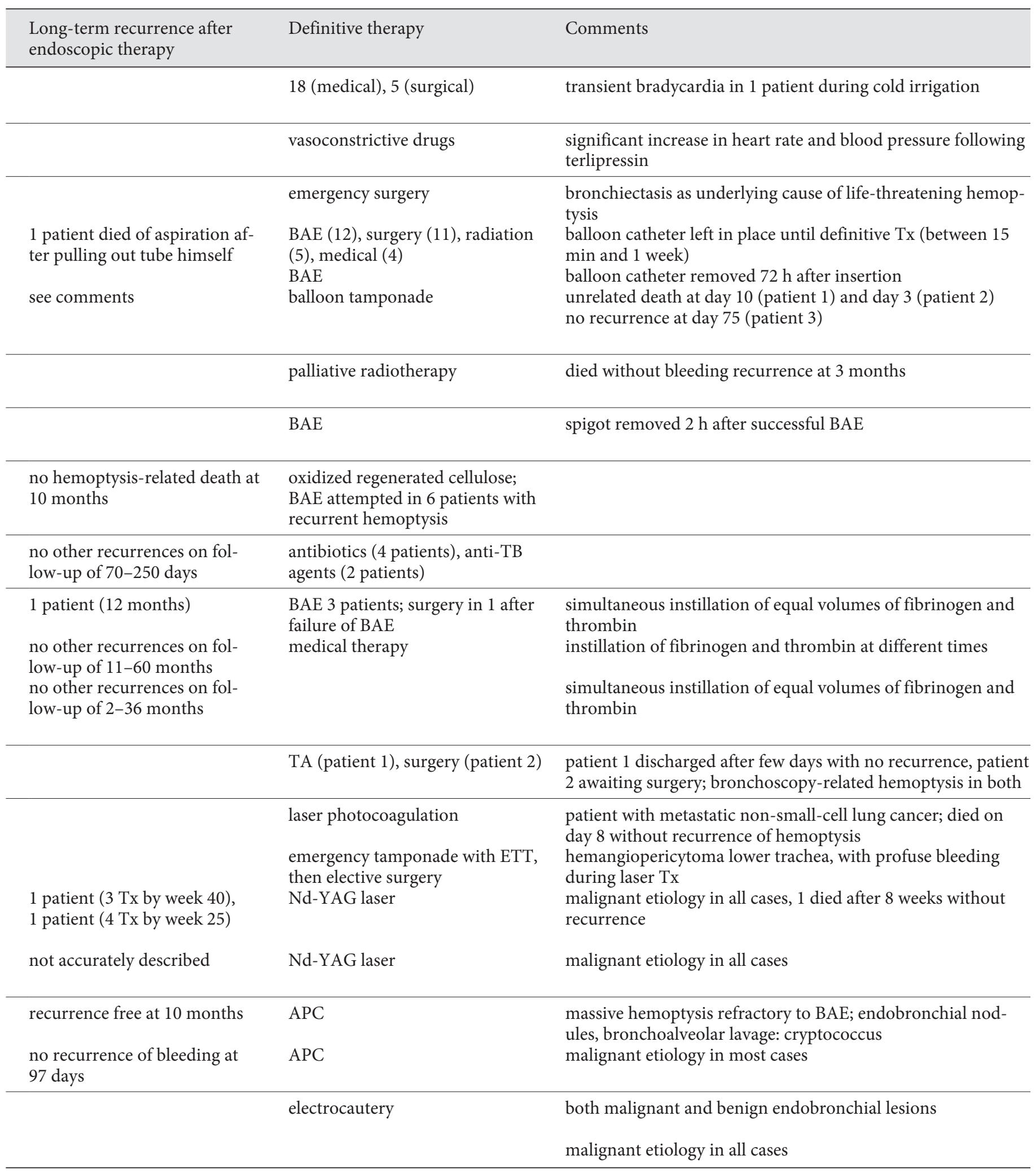


through a flexible fiber-optic bronchoscope in the right main bronchus, inflated and kept in place as an emergency measure in a hemodynamically unstable patient following bouts of severe hemoptysis. This enabled airway protection and resuscitation maneuvres before surgical resection of lung tissue exhibiting severe bronchiectasis.

More recently, Freitag et al. [86] developed a doublelumen bronchus-blocking balloon catheter, usually inserted into the working channel of a flexible fiber-optic bronchoscope. The second lumen of the catheter allows administration of cold saline, vasoactive drugs or other topical agents. A detachable double valve at the proximal end of the catheter allows safe removal of the flexible fiber-optic bronchoscope without displacement of the balloon catheter. Balloon tamponade was successful in 26/27 patients who lost at least $100 \mathrm{ml}$ of blood, and occlusion was feasible in main, lobar and segmental bronchi, and cavities. The catheter was kept in place between $15 \mathrm{~min}$ and 1 week, and was only deflated for a few minutes 3 times a day, in order to preserve mucosal viability and to check for bleeding recurrence. The catheter was left in position until patients underwent definitive therapy. Adverse effects consisted of lobar pneumonia in a patient whose catheter had been in place for 5 days, transient hoarseness in another patient because of granulation tissue on the vocal cords, and catheter migration in 3 patients, successfully managed by simple repositioning. Interestingly, bronchial artery embolization was facilitated as the inflated balloon prevented coughing of blood during the procedure.

Kato et al. [87] described a modified bronchoscopic balloon tamponade technique: an angiography J guide wire ( $0.035 \mathrm{in})$ is inserted through the working channel of a flexible fiber-optic bronchoscope, followed by removal of the bronchoscope and insertion of a balloon catheter $(7 \mathrm{Fr})$ over the guide wire into a segmental bronchus. The bronchoscope is then reinserted through the other nostril to check accurate catheter placement and balloon inflation. This technique was employed in a patient with massive hemoptysis $(1,500 \mathrm{ml} / 10 \mathrm{~h})$ after an unsuccessful classic catheter balloon tamponade due to decrerased suction capacity and vision once the catheter was introduced into the flexible fiber-optic bronchoscope.

Another balloon tamponade technique using a PA balloon catheter has been described. The catheter was introduced next to a flexible fiber-optic bronchoscope, guided through the endobronchial route, and inflated in segmental or subsegmental bronchi in 3 patients with mas- sive hemoptysis. The inflating pressure was measured with a manometer, aiming values around $30-50 \mathrm{~mm} \mathrm{Hg}$. In all 3 cases, the balloon was deflated after $48 \mathrm{~h}$, without recurrence of bleeding. However, the follow-up was short, i.e. 3, 10 and 75 days. A specific advantage offered by this technique is its ability to occlude more peripheral airways, such as subsegmental bronchi, thus minimizing gas exchange impairment [88].

\section{Endobronchial Stent Tamponade}

Successful tamponade and isolation of the bleeding site in a patient with massive hemoptysis has been achieved recently by the placement of two covered self-expanding airway stents. Bleeding originated from a left lower lobe cavitary non-small-cell lung cancer, and was confirmed by diagnostic FOB. Initially, a Polyflex stent of $8 \mathrm{~mm} \times$ $2 \mathrm{~cm}$ was deployed in the left lower lobe bronchus and expanded against segmental bronchi, resulting in a slight decrease in bleeding. This was followed by placement of an Ultraflex stent of $14 \mathrm{~mm} \times 6 \mathrm{~cm}$, extending from the proximal left main-stem bronchus to the left upper lobe bronchus, thus blocking the orifice of the left lower lobe bronchus. Following this procedure, bleeding into the proximal airways stopped, the patient was extubated and was able to undergo palliative radiotherapy. No recurrence of hemoptysis was reported in the last 4 months of the patient's life [89].

\section{Endobronchial Airway Blockade}

Silicone Spigot

Endobronchial placement of a silicone spigot has proved adequate for temporary control of bleeding, allowing patients to stabilize before endovascular embolization. Dutau et al. [90] reported the first case of its successful use in a young woman presenting with massive hemoptysis. A rigid bronchoscope initially allowed aspiration of blood and removal of clots in the right bronchial tree, following which bleeding started anew at the posterior segment of the right upper lobe. Cold saline and topical vasoactive agents were only partially effective in controlling bleeding, which prompted other treatment options. A flexible biopsy forceps was introduced through a flexible fiber-optic bronchoscope, with its distal end out of the bronchoscope, grasping a 6-mm silicone spigot. The flexible fiber-optic bronchoscope was then inserted into the rigid bronchoscope, and advanced towards the posterior segment of the right upper lobe, where the spigot was left in place under direct vision (fig. 2). Following this procedure, the patient underwent $\mathrm{BAE}$, and the spigot was removed $2 \mathrm{~h}$ later. 
Bronchoscopy-Guided Topical Hemostatic

Tamponade

Recently, topical hemostatic tamponade therapy, using oxidized regenerated cellulose mesh, a sterile kitted fabric, has been tried successfully in patients with lifethreatening hemoptysis [16]. This procedure was performed in patients with persistent hemorrhage despite bronchoscopic wedging into the bleeding bronchus, coldsaline lavage and local administration of epinephrine. The oxidized regenerated cellulose mesh was grasped with a biopsy forceps that had already been inserted into a flexible fiber-optic bronchoscope. It was then pulled back into the bronchoscope and introduced into the bleeding airway, ranging from lobar to subsegmental bronchi. An immediate arrest of the hemorrhage was achieved in 56 of 57 (98\%) patients, who remained free of hemoptysis for the first $48 \mathrm{~h}$. The only patient who had persistent hemoptysis despite hemostatic tamponade therapy underwent a successful surgical intervention. Mild to moderate bleeding $(<30-100 \mathrm{ml})$ recurred in 6 subjects (10.5\%) 3-6 days after the procedure. BAE was performed in all 6 , but failed to control bleeding in 2 of them. These 2 patients subsequently underwent repeat hemostatic tamponade therapy. Postobstructive pneumonia was observed in 5 patients, mainly in those who underwent tamponade of lobar bronchi (4 subjects). A subgroup of patients $(n=14)$ underwent repeat bronchoscopy 3-4 weeks after the procedure, and none of them suffered a recurrence of bleeding. In a mean follow-up of 10 months, no hemoptysis-related death was reported. It is worth noting that this approach is not suitable for proximal sites of bleeding such as the trachea, or in patients who cannot tolerate occlusion of the bleeding airway [91]. Moreover, concerns were expressed regarding the risk of late recurrence of hemoptysis since the oxidized regenerated cellulose mesh is absorbed [91].

Endobronchial Sealing with Biocompatible Glue

Endobronchial application of n-butyl cyanoacrylate, a biocompatible adhesive that solidifies on contact with humidity, has proved effective in controlling mild hemoptysis [92]. In a series of 6 patients with prolonged hemopty-

Fig. 2. Endobronchial embolization of the posterior segment of the right upper lobe with a silicone spigot as a temporary treatment for massive hemoptysis.

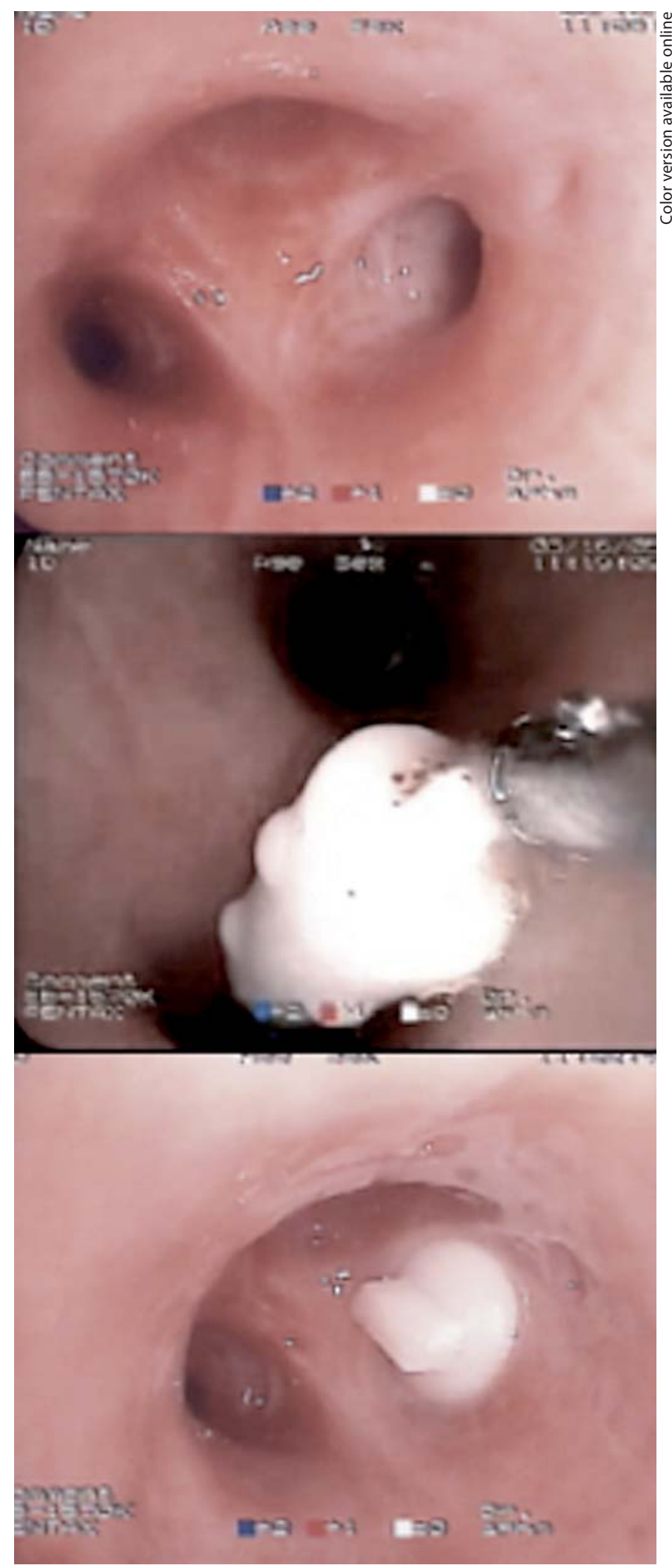

Respiration 2010;80:38-58 
Fig. 3. Rigid bronchoscopy for the endoscopic management of massive bleeding originating from a submucosal bronchial artery. a Flooding of the bronchus intermedius. b Use of a suction catheter for airway clearance and visualization of active bleeding arising from a bronchial artery. c While suctioning, laser allows simultaneous coagulation and devascularization of tissues surrounding the artery. d Finally, carbonization of the bleeding site.

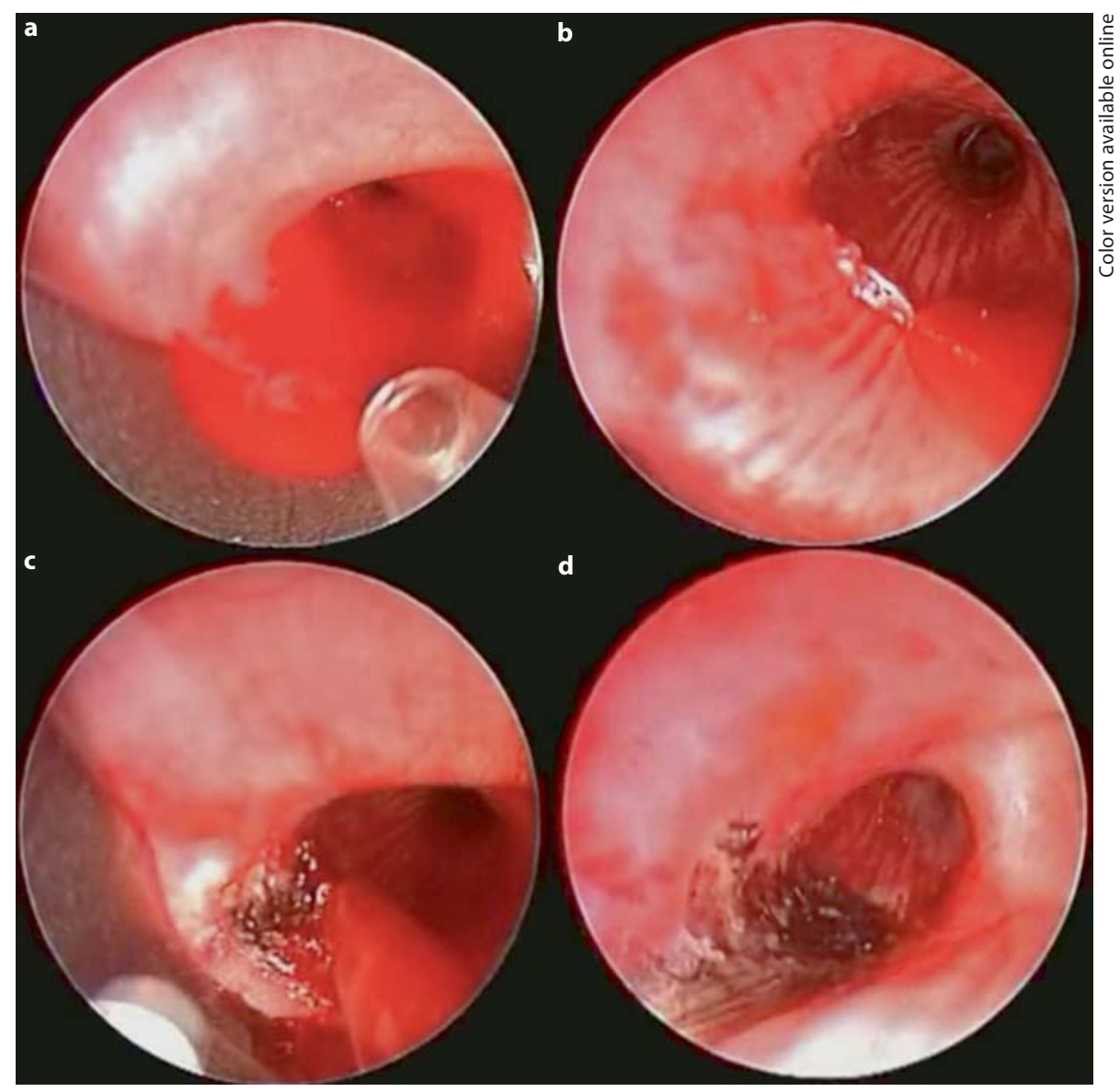

sis ( $>7$ days) despite conservative treatment, this material was injected into the bleeding airway through a catheter via a flexible fiber-optic bronchoscope. The bronchoscope was removed, and reintroduced few minutes later to check for persistent bleeding. The procedure was repeated until hemostasis was achieved. In all 6 patients, bleeding stopped following the procedure. A mild cough was reported by all subjects, as well as transient expectoration of granular material. Recurrence of bleeding was observed in 1 patient the same day, but was successfully managed by a repeat procedure. No other recurrences were noted during a follow-up of 70-250 days, except for 1 patient with known bronchiectasis, who experienced mild bleeding 1 month after the procedure and was treated conservatively. To our knowledge, no reports have described the use of this approach in massive hemoptysis.

\section{Laser Photocoagulation}

Nd-YAG laser has been employed since 1982, and was first introduced by Dumon et al. [93]. Nd-YAG laser co- agulation can be an effective treatment option for hemoptysis when the source of bleeding is bronchoscopically visible (fig. 3). It allows photocoagulation of the bleeding mucosa with resulting hemostasis, and can help achieve photoresection and vaporization of the underlying lesion, thus providing a definitive approach to hemoptysis management $[1,94]$. However, the use of laser photocoagulation for massive bleeding has provided mixed results [94, 95]. Edmondstone et al. [94] described successful management of life-threatening hemoptysis with bronchoscopic laser photocoagulation. Infrared light was applied on a hemorrhagic tumor in the right mainstem bronchus with complete hemostasis. On the other hand, Shankar et al. [95] failed to control an episode of profuse bleeding using this approach on a hemangiopericytoma in the lower trachea, and opted instead for tamponade of the bleeding area before elective surgical resection.

With regard to malignant tracheobronchial tumors, the main indications for endobronchial laser photocoagulation are endoluminal tumors presenting with symptom- 
atic airway obstruction and/or bleeding [46]. However, hemoptysis is rarely an indication for laser treatment on its own because most patients present with concomitant airway obstruction [96]. Despite this observation, several studies showed that laser therapy was very effective to photocoagulate tumor vessels, and thus control hemorrhage. Most of these studies, however, did not accurately assess bleeding severity. In a recent trial by Han et al. [97], improvement in hemoptysis was noted in $94 \%$ of cancer patients who underwent endobronchial Nd-YAG laser treatment, with complete cessation of bleeding in $74 \%$. Earlier studies, in which few patients were treated exclusively for hemoptysis, showed a response rate to laser therapy in the order of $60 \%[46,96]$. Hetzel and Smith [96] reported complete relief of hemoptysis for at least 1 month in 14 of $24(58 \%)$ patients with inoperable tracheobronchial tumors. Repeat courses of laser treatment were successful in case of relapse. Failure of laser therapy to stop the bleeding was often observed in patients with bronchoscopically invisible sites of hemorrhage.

\section{Argon Plasma Coagulation}

Argon plasma coagulation (APC) is a noncontact electrocoagulation tool. An argon plasma medium is employed to conduct high-frequency electrical current through a flexible probe. As blood is a good conductor for the high-frequency current, effective dessication of a bleeding bronchus can be performed. Once dessication of the targeted surface is achieved, it becomes less electrically conductive, thus preventing deeper penetration of the current, and damage or perforation to the underlying airway wall $[98,99]$. As in the case of YAG laser photocoagulation, APC should be used only when the source of bleeding is within the reach of the bronchoscope [100]. Although YAG laser provides deeper tissue penetration (5-10 vs. $2-3 \mathrm{~mm})[98,100]$ and higher temperatures allowing tissue vaporization, APC offers several advantages over YAG laser. It provides easy access to lesions located laterally or around anatomic corners [100]. In addition, it allows homogeneous tissue dessication because it continually seeks areas with higher water content and less electrical impedance.

In a retrospective study by Morice et al. [100], 31 patients with hemoptysis and 25 patients with both airway obstruction and hemoptysis were treated by endobronchial APC therapy. Bleeding was severe $(>200 \mathrm{ml} / 24 \mathrm{~h})$ in 6 patients, moderate $(>50-200 \mathrm{ml} / 24 \mathrm{~h})$ in 23 patients, and mild ( $\leq 50 \mathrm{ml} / 24 \mathrm{~h}$ ) but persisted for over a week in 27 patients. Airway hemorrhage stopped immediately after the procedure in all patients with an endoluminal source of bleeding. No recurrence of bleeding was observed on a mean follow-up period of 97 days. However, bleeding originating from a new endobronchial site was observed in 3 patients, and was treated successfully by APC. In 1 patient, the source of bleeding was not within the reach of the bronchoscope, and therefore BAE was performed after failure of APC. All patients had malignant underlying diagnoses, except for 2 patients who had telangiectasia and bronchiectasis as the source of bleeding.

In a recent case report, a heart transplantation patient with recurrent massive hemoptysis was unsuccessfully treated with BAE. Subsequent evaluation at a referral center revealed endobronchial hemorrhagic polypoid lesions which were treated with APC until dessication, with no further recurrence of bleeding in the 10 months of follow-up [99].

Although several other reports have described resolution of hemoptysis following APC treatment of endoluminal targets, bleeding episodes in most cases were mild to moderate, with benign underlying causes, namely endobronchial hemangiomas and endobronchial endometriosis with catamenial hemoptysis [101-103].

\section{Electrocautery}

Electrocautery to control hemoptysis has been mostly anecdotal. In a study of 56 patients with advanced lung cancer or benign tumors, control of hemoptysis using endobronchial electrocautery was achieved in $75 \%$ of the cases [104]. Sutedja et al. [105] reported successful management of hemoptysis in 4 patients treated with electrocautery for locally advanced tracheobronchial malignancies, without recurrence for the following 4 weeks. It is worth noting, however, that the magnitude of bleeding was not specified.

\section{Other Treatments: Cryotherapy and Brachytherapy}

Endobronchial cryotherapy has proved effective to manage hemoptysis in patients with inoperable endoluminal malignancies [106-108]. In fact, freezing has been shown to cause vasoconstriction and development of microthrombi in venules and capillaries, which might explain the efficacy of cryotherapy for obtaining hemostasis [109]. In addition, successful removal of blood clots has been achieved using this approach [110]. However, because of its delayed effect, cryotherapy has no role in the management of massive hemoptysis [46].

Brachytherapy, although effective as a palliation treatment for hemoptysis in advanced lung cancer, is not a treatment option either for massive bleeding [111]. 
Fig. 4. Left upper lobe bronchial artery before (a) and after (b) bronchial artery embolization for massive hemoptysis.

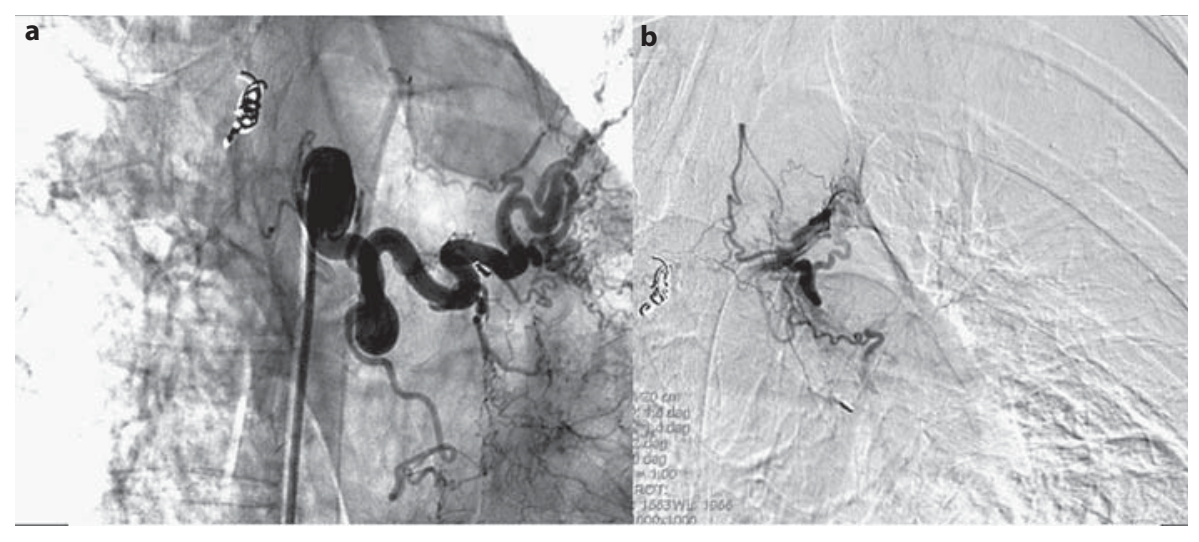

\section{Bronchial Artery Embolization}

BAE for the management of hemoptysis was first performed by Remy et al. [112] in 1973. The first large series published by this group in 1977 reported the outcome of 104 patients who underwent embolization of bronchial and nonbronchial arteries for the control of massive or recurrent hemoptysis [113]. Forty-nine patients were treated during active hemoptysis, with immediate arrest of bleeding in 41 patients. Six of these patients had recurrent episodes of bleeding 2-7 months after the initial procedure. Since then, BAE has been widely used to control massive hemoptysis, as a temporary measure to stabilize patients before surgical resection or medical treatment (antibiotics/antituberculous drugs) or as a definitive therapeutic approach in patients who refuse surgery, who are not considered as candidates for surgery (poor lung function, bilateral pulmonary disease, comorbidities), or patients in whom surgery is contraindicated (fig. 4).

Immediate control of hemoptysis with BAE has been reported in $57-100 \%$ of patients $[12,26,44,113-121]$. This wide range of success rates across studies can be partially attributed to heterogeneity with regard to analysis of results [122]. In some studies, patients in whom the procedure was attempted, even though it was not completed because of technical difficulties, were accounted for in the final calculations of success rates [12, 26, 114, 122]. This intent-to-treat analysis might explain the lower success rates in the study by Mal et al. [12]. In some of the other series reporting higher success rates, no details were provided with regard to patients in whom BAE was initiated but not completed [115-117]. Reasons for abandoning the procedure after an initial attempt were failure to cannulate the bronchial artery or to achieve a stable catheter position within its lumen, and visualization of a spinal artery branch arising from a bronchial artery [12, $114,118]$. However, since the mid 1990s, a 'super-selective' technique with the use of a 3 -french microcatheter to cannulate smaller caliber vessels has been developed and widely employed. This technique allows a more stable position within the bronchial circulation, and permits cannulation of a bronchial artery distally to the origin of a spinal branch, therefore avoiding neurological complications [117].

Although bleeding recurrence after BAE has been described in $10-29 \%$ of patients at 1-month follow-up [12, $26,114]$, the procedure can be repeated safely [114]. Barben et al. [121] reported the need of a second embolization in $55 \%(11 / 20)$ of their cystic fibrosis patients, with a median time interval of 4 months between the first and second procedures. Recurrence of hemoptysis may be due to incomplete embolization of the bronchial vessels, recannalization of the embolized arteries, presence of nonbronchial systemic arteries, or development of collateral circulation in response to continuing pulmonary inflammation $[12,114,115,123]$. Therefore, some authors advocate thorough embolization, including embolization of nonbronchial systemic arteries which might have contributed to the bleeding episode, in addition to careful evaluation and treatment of the underlying pulmonary condition. It has been postulated that recurrence rates may be related to the etiology of hemoptysis. Several studies have found that bleeding anew after BAE occurred more often in patients with bronchogenic carcinomas $[26,114,118]$. Others have reported higher rates of recurrence in patients with aspergillomas $[26,124]$.

It is worth noting that persistent or recurrent hemoptysis following BAE may also suggest bleeding of PA origin $[28,125]$, a finding that could have been missed or misinterpreted on radiological work-up (e.g. multidetec- 
tor $\mathrm{CT}$ ). If this diagnostic entity is confirmed, PA embolization should be performed to ensure timely control of hemoptysis. Unlike endovascular treatment, however, surgical management excludes the risk of recurrent PA bleeding [126]. This is particularly true for unpredictable massive bleeding episodes in the context of necrotizing lung infections such as mycetomas, where resection is the only definitive treatment strategy for recurrent hemoptysis. The majority of patients with aspergilloma will bleed anew after some time if they are not treated surgically. $\mathrm{BAE}$ is, therefore, a temporary treatment strategy for massive hemoptysis in such patients. Aspergilloma will almost always require surgery following urgent BAE Massive hemoptysis in patients with aspergilloma has been associated with a $25-30 \%$ mortality rate [128]. In recent studies, surgical resection of aspergillomas in patients with severe hemoptysis has been successfully achieved with a low intraoperative mortality rate $[128$, 129]. PA hemorrhage in the context of resectable lung tumors is another indication for prompt surgical resection following initial endovascular management [46].

On the other hand, pulmonary arteriovenous malformation - another well-recognized cause of massive hemoptysis of PA origin - has been shown to respond favorably to PA embolization with a satisfactory long-term outcome, therefore avoiding surgical resection. In a study by Haitjema et al. [130], where 92 pulmonary arteriovenous malformations in 32 patients were treated by coil embolization, significant improvement in arterial oxygen tension and shunt fraction were observed. Interestingly, recannalization of embolized vessels occurred in only 2 patients after 22 and 28 months. The mean followup was 25 months.

Procedure-related complications are rare $(<5 \%)$ and include transient pyrexia and chest pain $[12,114]$, transient dysphagia [114], groin hematoma [114], subintimal dissection or perforation of arteries by the guidewire [12, 114], and transient or sometimes permanent neurological deficits $[12,14,26,49]$. Although neurological complications are the most dreaded adverse effects, their incidence has significantly decreased since the wide use of the 'super-selective' technique which enables distal cannulation of the target vessel, beyond the origin of spinal branches [123].

\section{Surgery}

Emergency surgery for the management of massive hemoptysis has been gradually abandoned because of the high morbidity and mortality ranging between 20 and $30 \%[7,8,131]$ and the advent of safe and effective alternative endovascular techniques. In addition, surgical resection is not an option for patients with poor functional status, moderate to severe lung function impairment, bilateral pulmonary disease or other comorbidities.

Currently, surgery is mainly reserved for cases of technical failure of arteriography as outlined above $[26,44]$, early or repeated recurrences of hemoptysis despite BAE $[26,44]$, or in extreme situations where the amount of bleeding or the patient's cardiopulmonary status are deemed life-threatening and do not allow transfer to an interventional radiology suite or any related delays in management [1]. In a recent study by Ong and Eng [13], only 4 of 31 patients (12\%) underwent emergent surgical procedures for the control of bleeding after failure of repeated BAE procedures, with an overall in-hospital mortality rate of $13 \%$. A similar approach was used by Fartoukh et al. [26], who only treated 23 of 196 (12\%) patients with surgical resection. Reported intensive care unit and hospital mortality rates were 4 and $8 \%$, respectively. In a recent study, where surgical management of massive hemoptysis was avoided in the first $48 \mathrm{~h}$ and conducted only after technical failure or early relapse following BAE, lower in-hospital mortality (0\%) and surgical morbidity $(18 \%)$ rates were observed in comparison with earlier studies favoring surgery as first-line therapy [5].

Surgery also remains the strategy of choice for the management of massive hemoptysis caused by diffuse and complex arteriovenous malformations, iatrogenic PA rupture, chest trauma, and mycetoma not responding to other therapeutic strategies, or associated with recurrent life-threatening hemoptysis as outlined above [59]. Bronchovascular fistulas with ensuing massive bleeding - most often encountered following surgery, local infection, associated with vascular aneurysms, and less frequently following lung transplantation surgery - are also managed by surgical repair once the patient is stabilized. However, endovascular stent grafting has been performed since 1994 for aortobronchial fistulas with satisfactory results, and lower mortality and complication rates [132-135].

\section{Therapeutic Strategy Algorithm}

Although there is no consensus on a precise definition of massive hemoptysis, it should always be regarded as a life-threatening condition requiring timely management through efficient multidisciplinary efforts and collabora- 


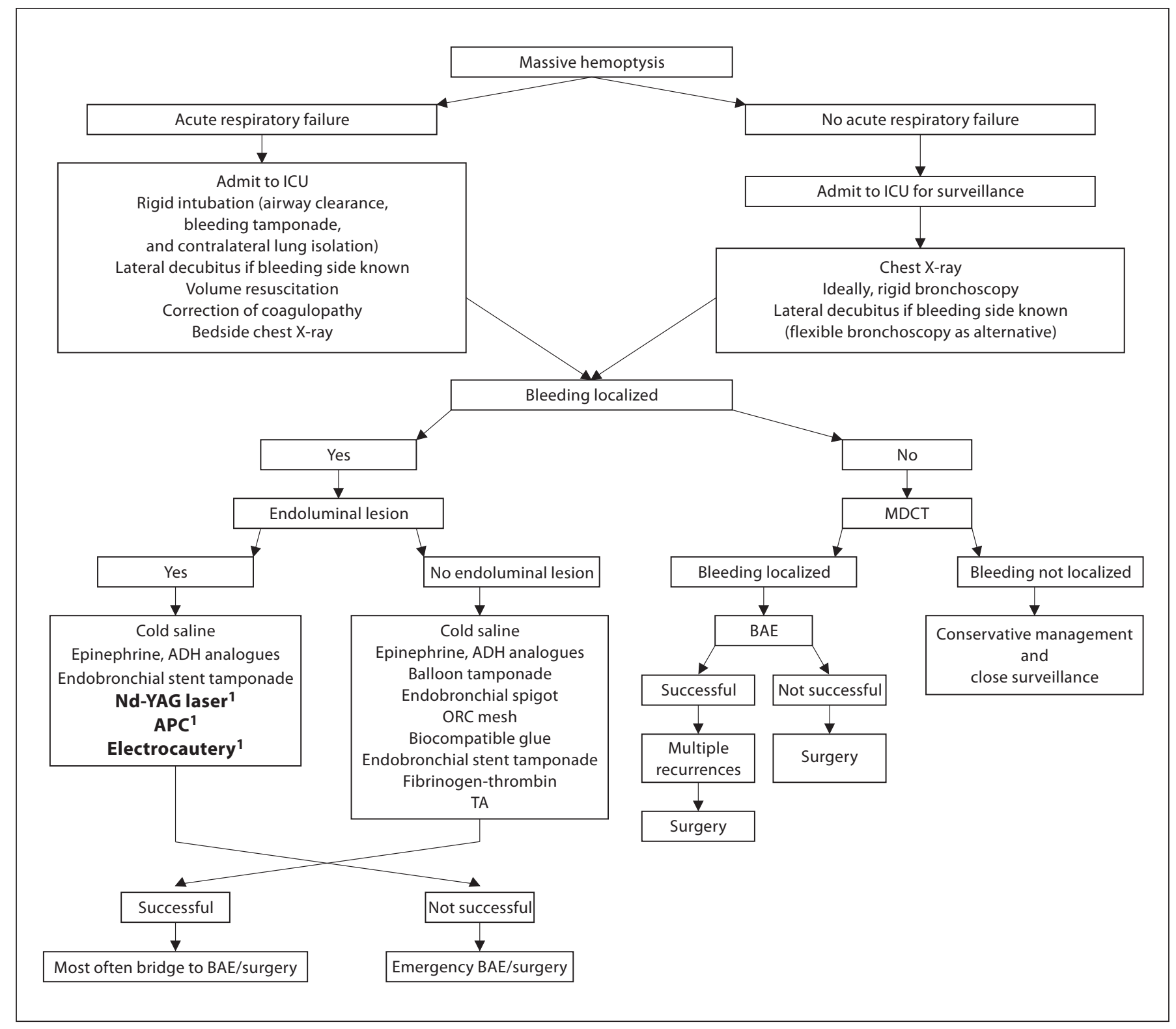

Fig. 5. Algorithm of multidisciplinary management of massive hemoptysis. $\mathrm{ICU}=$ Intensive care unit; $\mathrm{ADH}=$ antidiuretic hormone; ORC mesh $=$ oxidized regenerated cellulose mesh. $\mathrm{MDCT}=$ multidetector CT. ${ }^{1}$ Exclusively for visible endoluminal lesions.

tion (fig. 5). The initial approach consists of assessing and stabilizing the patient's condition through effective airway protection and volume resuscitation. Rigid bronchoscopy is the most effective initial procedure in patients with massive hemoptysis associated with hemodynamic compromise and respiratory instability, as it is the only means to efficiently clear the airways from clotted blood and secretions, to isolate the nonaffected lung, thereby preserving adequate ventilation, and to perform rapid and efficient tamponade of the bleeding lobar bronchus. In addition, introduction of a flexible fiber-optic bronchoscope through the rigid tube might allow better inspection of the upper lobes and peripheral airways. A chest radiograph might provide complementary information. A CT scan of the chest requires transfer to the radiology suite, thusdelaying patient care. It should be 
performed, however, once patients are stabilized, in cases where neither chest radiograph nor bronchoscopy has provided diagnostic clues regarding the site or etiology of bleeding. An effective consultation with interventional radiologists and thoracic surgeons is mandatory for better treatment strategy planning. It is worth noting that while some procedures can be performed for temporary control of bleeding originating from bronchoscopically invisible lesions (cold saline, endobronchial instillation of vasoconstrictive agents, TA, fibrinogen-thrombin solution, balloon tamponade, endobronchial spigot, biocompatible glue, oxidized regenerated cellulose and endobronchial stent placement), others, such as Nd-YAG laser treatments, APC and electrocautery, can only be applied directly to the lesion in order to coagulate underlying vessels. Stent placement can be performed as well in case of endoluminal lesions, providing an effective local tamponade. Although appealing in our era of noninva- sive therapy, endobronchial management strategies have not been validated by randomized controlled trials. They can be initiated for the early management of massive hemoptysis, until more definitive endovascular or surgical therapies become available. In a recent trial, airway clearance with rigid bronchoscopy before surgical resection contributed to lower in-hospital mortality and lower surgical morbidy [5]. Early bronchoscopic management can therefore improve patient outcome, even as a temporary measure to control bleeding. In some cases, however, bronchoscopic techniques might provide long-lasting hemostasis in patients not deemed suitable for other treatment strategies. Currently, BAE is considered a first-line definitive procedure for managing hemoptysis, with the few exceptions outlined above. Surgery, as a salvage strategy, is indicated after failure of BAE and is associated with better survival when performed in a nonurgent setting.

\section{References}

1 Dweik R, Stoller JK: Role of bronchoscopy in massive hemoptysis. Clin Chest Med 1999; 20:89-105.

-2 Amirana M, Frater R, Tirschwell P, Janis M, Bloomberg A, State D: An aggressive surgical approach to significant hemoptysis in patients with pulmonary tuberculosis. Am Rev Respir Dis 1968;97:187-192.

$\checkmark 3$ Bobrowitz ID, Ramakrishna S, Shim YS: Comparison of medical vs. surgical treatment of major hemoptysis. Arch Intern Med 1983;143:1343-1346.

4 Corey R, Hla KM: Major and massive hemoptysis: reassessment of conservative management. Am J Med Sci 1987;294:301-309.

5 Shigemura N, Wan IY, Yu SCH: Multidisciplinary management of life-threatening massive hemoptysis: a 10-year experience. Ann Thorac Surg 2009;87:849-853.

6 Flume PA, Yankaskas JR, Ebeling M, Hulsey T, Clark LL: Massive hemoptysis in cystic fibrosis. Chest 2005;128:729-738.

7 Crocco JA, Rooney JJ, Fankushen DS, et al: Massive hemoptysis. Arch Intern Med 1968; 121:495-498.

$>8$ Garzon AA, Gourin A: Surgical management of massive hemoptysis: a ten-year experience. Ann Surg 1978;187:267-271.

-9 Hirshberg B, Biran I, Glazer M, Kramer MR: Hemoptysis: etiology, evaluation, and outcome in a tertiary referral hospital. Chest 1997;112:440-444.

-10 de Gracia J, de la Rosa D, Catal!an E, Alvarez A, Bravo C, Morell F: Use of endoscopic fibrinogen-thrombin in the treatment of severe hemoptysis. Respir Med 2003;97:790795.
11 Garzon AA, Cerruti MM, Golding ME: Exsanguinating hemoptysis. J Thorac Cardiovasc Surg 1982;84:829-833.

12 Mal H, Rullon I, Mellot F, Brugière O, Sleiman C, Menu Y, Fournier M: Immediate and long-term results of bronchial artery embolization for life-threatening hemoptysis. Chest 1999;115:996-1001.

13 Ong TH, Eng P: Massive hemoptysis requiring intensive care. Intensive Care Med 2003. 29:317-320.

14 Brinson GM, Noone PG, Mauro MA Knowles MR, Yankaskas JR, Sandhu JS, Jacques PF: Bronchial artery embolization for the treatment of hemoptysis in patients with cystic fibrosis. Am J Respir Crit Care Med 1998;157:1951-1958.

15 Knott-Craig CJ, Oostuizen G, Rossouw G, Joubert JR, Barnard PM: Management and prognosis of massive hemoptysis: recent experience with 120 patients. J Thorac Cardiovasc Surg 1993;105:394-397.

16 Valipour A, Kreuzer A, Koller H, Koessler W, Burghuber OC: Bronchoscopy-guided topical hemostatic tamponade therapy for the management of life-threatening hemoptysis. Chest 2005; 127:2113-2118.

$\checkmark 17$ Revel MP, Fournier LS, Hennebicque AS, Cuenod CA, Meyer G, Reynaud P, Frija G: Can CT replace bronchoscopy in the detection of the site and cause of bleeding in patients with large or massive hemoptysis? AJR Am J Roentgenol 2002;179:1217-1224.

18 Conlan AA, Hurwitz SS: Management of massive haemoptysis with the rigid bronchoscope and cold saline lavage. Thorax 1980; 35:901-904.
19 Khalil A, Soussan M, Mangiapan G, Fartoukh M, Parrot A, Carette MF: Utility of high-resolution chest CT scan in the emergency management of hemoptysis in the intensive care unit: severity, localization and aetiology. BJR 2007;80:21-25.

$>20$ Ibrahim WH: Massive hemoptysis: the definition should be revised. Eur Respir J 2008; 32:1131-1132.

21 Holsclaw DS, Grand RJ, Shwachman H: Massive hemoptysis in cystic fibrosis. J Pediatr 1970;76:829-838.

22 Remy J, Remy-Jardin M, Voisin C: Endovascular management of bronchial bleeding; in Butler J (ed): The Bronchial Circulation. New York, Dekker, 1992, pp 667-723.

$\checkmark 23$ Khalil A, Parrot A, Nedelcu C, Fartoukh M, Marsault C, Carette MF: Severe hemoptysis of pulmonary arterial origin:Signs and role of multidetector row CT. Chest 2008;133: 212-219.

24 Cauldwell EW, Sickert RG, Lininger RE, et al: The bronchial arteries: an anatomic study of 150 human cadavers. Surg Gynecol Obstet 1948;86:395-412.

-25 Deffenbach ME, Charan NB, Lakshminarayan S, Butler J: The bronchial circulation: small, but a vital attribute to the lung. Am Rev Respir Dis 1987;135:463-481.

26 Fartoukh M, Khalil A, Louis L, et al: An integrated approach to diagnosis and management of severe haemoptysis in patients admitted to the intensive care unit: a case series from a referral centre. Respir Res 2007;8:1120 . 
27 McGuinness G, Beacher JR, Harkin TJ: Hemoptysis: prospective high resolution $\mathrm{CT} /$ bronchoscopic correlation. Chest 1994;105: $1155-1162$.

28 Rabkin JE, Astafjev VI, Gothman LN, et al: Transcatheter embolization in the management of pulmonary hemorrhage. Radiology 1987;163:361-365.

29 Remy-Jardin M, Wattinne L, Remy J: Transcatheter occlusion of pulmonary arterial circulation and collateral supply: failures, incidents, and complications. Radiology 1991; 180:699-705.

-30 Uzun O, Erkan L, Akpolat I, et al: Pulmonary involvement in Behçet's disease. Respiration 2008;75:310-321.

- 31 Fleisher AG, Tyers GF, Manning GT, et al: Management of massive hemoptysis secondary to catheter-induced perforation of the pulmonary artery during cardiopulmonary bypass. Chest 1989;95:1340-1341.

- 32 Abreu AR, Campos MA, Krieger BP: Pulmonary artery rupture induced by a pulmonary artery catheter: a case report and review of the literature. J Intensive Care Med 2004;19: 291.

33 Ference BA, Shannon TM, White RL, et al: Life-threatening pulmonary hemorrhage with pulmonary arteriovenous malformations and hereditary hemorrhagic telangiectasia. Chest 1994;106;5:1387-1390.

- 34 Cottin V, Dupuis-Girod S, Lesca G, et al: Pulmonary vascular manifestations of hereditary hemorrhagic telangiectasia (RenduOsler disease). Respiration 2007;74:361378.

- 35 Sbano H, Mitchell AW, Ind PW, et al: Periph eral pulmonary artery pseudoaneurysms and massive hemoptysis. AJR 2005; 184: 1253-1259.

-36 Samano MN, Minamoto H, Junqueira JJM. Bronchial complications following lung transplantation. Transplant Proc 2009;41: 921-926.

- 37 Slatore CG, Yank W, Jewell KD: Bronchialpulmonary artery fistula with fatal massive hemoptysis caused by anastomotic bronchial aspergillus infection in a lung transplant recipient. Resp Care 2007;52:1542-1545.

38 Guth S, Mayer E, Fischer B: Bilobectomy for massive hemoptysis after bilateral lung transplantation. J Thorac Cardiovasc Surg 2001;121:1194-1195

- 39 Picard C, Parrot A, Boussaud V: Massive hemoptysis due to Rasmussen aneurysm: detection with helicoidal CT angiography and successful steel coil embolization. Intensive Care Med 2003;29:1837-1839.

40 Keeling AN, Costello R, Lee MJ: Rasmussen's aneurysm: a forgotten entity? Cardiovasc Intervent Radiol 2008;31:196-200.

-41 Iwata T, Inoue K, Nishiyama N, et al: Late massive hemoptysis after transbronchial biopsy of hamartoma: an involvement of pulmonary artery and vein. Ann Thorac Cardiovasc Surg 2007;13:400-402.
42 Mohit C, Getzen T, Simoff MJ: Medical pneumonectomy, interventional bronchoscopic and endovascular management of massive hemoptysis due to pulmonary artery pseudoaneurysm, a consequence of endobronchial brachytherapy. Chest 2009;135 1355-1358.

43 Yamakado K, Takaki H, Takao M, et al: Massive hemoptysis from pulmonary artery pseudoaneurysm caused by lung radiofrequency ablation: successful treatment by coil embolization. Cardiovasc Intervent Radiol 2009 May 5. Epub ahead of print.

44 Savale L, Parrot A, Khalil A, et al: Cryptogenic hemoptysis: from a benign to a lifethreatening pathologic vascular condition. Am J Respir Crit Care Med 2007;175:11811185.

45 Johnston H, Reisz G: Changing spectrum of hemoptysis: underlying causes in $148 \mathrm{pa}-$ tients undergoing diagnostic flexible bronchoscopy. Arch Intern Med 1989;149:16661668.

46 Kvale PA, Selecky PA, Prakash UB: American College of Chest Physicians. Palliative care in lung cancer: ACCP evidence-based clinical practice guidelines (2nd edition) Chest 2007;132(suppl):368S-403S

47 Lee TW, Wan S, Choy DK: Management of massive hemoptysis: a single institution experience. Ann Thorac Cardiovasc Surg 2000; 6:232-235.

48 Osakia SI, Nakanishia Y, Watayaa H: Prognosis of bronchial artery embolization in the management of hemoptysis. Respiration 2000;67:412-416.

49 Wang GR, Ensor JE, Gupta S, Hicks ME, Tam AL: Bronchial artery embolization for the management of hemoptysis in oncology patients: utility and prognostic factors. J Vasc Interv Radiol 2009;20:722-729.

50 Van den Heuvel MM, Els Z, Koegelenberg CF: Risk factors for recurrence of haemoptysis following bronchial artery embolisation for life-threatening haemoptysis. Int $\mathrm{J} \mathrm{Tu}-$ berc Lung Dis 2007;11:909-914.

51 Gross AM, Diacon AH, van den Heuvel MM: Management of life-threatening haemoptysis in an area of high tuberculosis incidence. Int J Tuberc Lung Dis 2009;13:875-880.

52 Hsiao EI, Kirsch CM, Kagawa FT, Wehner $\mathrm{JH}$, Jensen WA, Baxter RB: Utility of fiberoptic bronchoscopy before bronchial artery embolization for massive hemoptysis. AJR Am J Roentgenol 2001;177:861-867.

53 Haponik EF, Britt EJ, Smith PL, Bleecker ER: Computed chest tomography in the evaluation of hemoptysis: impact on diagnosis and treatment. Chest 1987;91:80-85.

54 Marshall TJ, Flower CD, Jackson JE: The role of radiology in the investigation and management of patients with haemoptysis. Clin Radiol 1996;51:391-400.

- 55 Naidich DP, Funt S, Ettenger NA, Arranda C: Hemoptysis: CT-bronchoscopic correlations in 58 cases. Radiology 1990;177:357-362.
56 Yoon YC, Lee KS, Jeong YJ, Shin SW, Chung MJ, Kwon OJ: Hemoptysis: bronchial and nonbronchial systemic arteries at 16-detector row CT. Radiology 2005;234:292-298.

57 Remy-Jardin M, Bouaziz N, Dumont P, Brillet PY, Bruzzi J, Remy J: Bronchial and nonbronchial systemic arteries at multi-detector row CT angiography: comparison with conventional angiography. Radiology 2004;233: 741-749.

- 58 Yoon W, Kim YH, Kim JK, Kim YC, Park JG, Kang HK: Massive hemoptysis: prediction of nonbronchial systemic arterial supply with chest CT. Radiology 2003;227:232-238.

59 Jean-Baptiste, E: Clinical assessment and management of massive hemoptysis. Crit Care Med 2000;28:1642-1647.

60 Gong H Jr, Salvatierra C: Clinical efficacy of early and delayed fiberoptic bronchoscopy in patients with hemoptysis. Am Rev Respir Dis 1981;124:221-225.

61 Saumench J, Escarrabil J, Padro L, et al: Value of fiberoptic bronchoscopy and angiography for diagnosis of the bleeding site in hemoptysis. Ann Thorac Surg 1989;48:272274.

62 Lordan JL, Gascoigne A, Corris PA: The pulmonary physician in critical care. Illustrative case 7: assessment and management of massive haemoptysis. Thorax 2003;58:814819.

-63 Cordasco EM Jr, Mehta AC, Ahmad M: Bronchoscopically induced bleeding. A summary of nine years' Cleveland clinic experience and review of the literature. Chest 1991; 100:1141-1147.

64 Pastis NJ, Nietert PJ, Silvestri GA: Variation in training for interventional pulmonary procedures among US pulmonary/critical care fellowships: a survey of fellowship directors. Chest 2005;127:1614-1621.

65 Sharma S, Dhar A, McLean L, Sahni P, Lertzman M: Practice patterns of respirologists in Canada. Can Respir J 2002;9:395-400.

-66 Conlan AA, Hurwitz SS, Krige L, Nicolaou N, Pool R: Massive hemoptysis: review of 123 cases. J Thorac Cardiovasc Surg 1983;85: 120-124.

-67 BreuerHW, Charchut S, Worth H, Trampisch HJ, Glänzer K: Endobronchial versus intravenous application of the vasopressin derivative glypressin during diagnostic bronchoscopy. Eur Respir J 1989;2:225-228.

68 Zavala DC: Pulmonary hemorrhage in fiberoptic transbronchial biopsy. Chest 1976;70: 584-588.

69 Tüller C, Tüller D, Tamm M, Brutsche MH: Hemodynamic effects of endobronchial application of ornipressin versus terlipressin. Respiration 2004;71:397-401.

70 Cahill BC, Ingbar DH: Massive hemoptysis. Assessment and management. Clin Chest Med 1994;15:147-167. 
-71 Mazkereth R, Paret G, Ezra D, et al: Epinephrine blood concentrations after peripheral bronchial versus endotracheal administration of epinephrine in dogs. Crit Care Med 1992;20:1582-1587.

-72 Kalyanaraman M, Carpenter RL, McGlew MJ, Guertin SR: Cardiopulmonary compromise after use of topical and submucosal $\alpha$ agonists: possible added complication by the use of $\beta$-blocker therapy. Otolaryngol Head Neck Surg 1997;117:56-61.

-73 Sharkey AJ, Brennen MD, O’Neill MP, et al: A comparative study of the haemostatic properties and cardiovascular effects of adrenaline and ornipressin in children using enflurane anaesthesia. Acta Anaesthesiol Scand 1982;26:368-370.

-74 Mannucci PM: Hemostatic drugs. N Engl J Med 1998;339:245-253.

-75 Wong LT, Lillquist YP, Culham G, DeJong BP, Davidson AG: Treatment of recurrent hemoptysis in a child with cystic fibrosis by repeated bronchial artery embolizations and long-term tranexamic acid. Pediatr Pulmonol 1996;22:275-279.

-76 Chang AB, Ditchfield M, Robinson PJ, Robertson CF: Major hemoptysis in a child with cystic fibrosis from multiple aberrant bronchial arteries treated with tranexamic acid. Pediatr Pulmonol 1996;22:416-420.

-77 Graff GR: Treatment of recurrent severe hemoptysis in cystic fibrosis with tranexamic acid. Respiration 2001;68:91-94.

-78 Sindet-Pedersen S, Ramstrom G, Bernvil S, et al: Hemostatic effect of tranexamic acid mouthwash in anticoagulant-treated patients undergoing oral surgery. $\mathrm{N}$ Engl J Med 1989;320:840-843.

-79 Ramsrrom G, Sindet-Pedersen S, Hall G, Blombäck M, Alander U: Prevention of postsurgical bleeding in oral surgery using tranexamic acid without dose modification of oral anticoagulants. J Oral Maxillofac Surg 1993;51:1211-1216.

-80 De Boer WA, Koolen MGJ, Roos CM, et al: Tranexamic acid treatment of hemothorax in two patients with malignant mesothelioma. Chest 1991;100:847-848.

-81 Solomonov A, Fruchter O, Zuckerman T, Brenner B, Yigla M: Pulmonary hemorrhage: a novel mode of therapy. Respir Med 2009; 103:1196-1200.

-82 Tsukamoto T, Sasaki H, Nakamura H: Treatment of hemoptysis patients by thrombin and fibrinogen-thrombin infusion therapy using a fiberoptic bronchoscope. Chest 1989; 96:473-476.

83 Bense L: Intrabronchial selective coagulative treatment of hemoptysis. Chest 1990;97: 990-996.

84 Hiebert C: Balloon catheter control of lifethreatening hemoptysis. Chest 1974;66:308309.

85 Gottlieb L, Hillberg R: Endobronchial tamponade therapy for intractable hemoptysis. Chest 1975;67:482-483.
86 Freitag L, Tekolf E, Stamatis G, Montag M, Greschuchna D: Three years experience with a new balloon catheter for the management of haemoptysis. Eur Respir J 1994;7: 2033-2037.

-87 Kato R, Sawafuji M, Kawamura M, Kikuchi K, Kobayashi K: Massive hemoptysis successfully treated by modified bronchoscopic balloon tamponade technique. Chest 1996; 109:842-843.

88 Jolliet P, Soccal P, Chevrolet JC: Control of massive hemoptysis by endobronchial tamponade with a pulmonary artery balloon catheter. Crit Care Med 1992;20:17301732.

89 Brandes JC, Schmidt E, Yung R: Occlusive endobronchial stent placement as a novel management approach to massive hemoptysis from lung cancer. J Thorac Oncol 2008;3:1071-1072.

90 Dutau H, Palot A, Haas A, Decamps I, Durieux O: Endobronchial embolization with a silicone spigot as a temporary treatment for massive hemoptysis. Respiration 2006; 73:830-832.

91 George Reisz: Topical hemostatic tamponade. Chest 2005;127:1888-1889.

$\$ 2$ Bhattacharyya P, Dutta A, Samanta AN, Chowdhury SR: New procedure: bronchoscopic endobronchial sealing; a new mode of managing hemoptysis. Chest 2002;121: 2066-2069.

\$3 Dumon JF, Reboud E, Garbe L, Aucomte F, Meric B: Treatment of tracheobronchial lesions by laser photoresection. Chest 1982; 81:278-284.

$\$ 94$ Edmondstone WM, Nanson EM, Woodcock AA, Millard FJ, Hetzel MR: Lifethreatening haemoptysis controlled by laser photocoagulation. Thorax 1983;38: 788-789.

-95 Shankar S, George PJM, Hetzel MR, Goldstraw $P$ : Elective resection of tumours of the trachea and main carina after endoscopic laser therapy. Thorax 1990;45:493-495.

-96 Hetzel MR, Smith SGT: Endoscopic palliation of tracheobronchial malignancies. Thorax 1991;46:325-333.

$\$ 97$ Han CC, Prasetyo D, Wright GM: Endobronchial palliation using Nd-YAG laser is associated with improved survival when combined with multimodal adjuvant treatments. J Thorac Oncol 2007;2:59-64.

$\$ 98$ Freitag L: Interventional endoscopic treatment. Lung Cancer 2004;45:S235-S238.

$\$ 99$ Keller CA, Hinerman R, Singh A, Alvarez F: The use of endoscopic argon plasma coagulation in airway complications after solid organ transplantation. Chest 2001;119: 1968-1975.

100 Morice RC, Ece T, Ece F, Keus L: Endobronchial argon plasma coagulation for treatment of hemoptysis and neoplastic airway obstruction. Chest 2001;119:781-787.
101 Rose AS, Mathur PN: Endobronchial capillary hemangioma: case report and review of the literature. Respiration 2008;76:221224.

102 Ozvaran MK, Baran R, Sogukpmar O, Uzman O, Sahin K, Kocadelioglu I, Aksoy F, Altun S: Histopathological diagnosis of endobronchial endometriosis treated with argon laser. Respirology 2006;11:348-350.

103 DeKeratry DR: Argon plasma coagulation for endobronchial hemangioma, a new treatment option for a rare cause of hemoptysis. J Bronchol 2004;11:254-256.

104 Homasson JP: Endobronchial electrocautery. Semin Respir Crit Care 1997;18:535543.

105 Sutedja G, van Kralingen K, Schramel FM, Postmus PE: Fibreoptic bronchoscopic electrosurgery under local anaesthesia for rapid palliation in patients with central airway malignancies: a preliminary report. Thorax 1994;49:1243-1246.

106 Mathur PN, Wolf KM, Busk MF, Briete WM, Datzman M: Fiberoptic bronchoscopic cryotherapy in the management of tracheobronchial obstruction. Chest 1996; 110:718-723.

107 Maiwand MO, Asimakopoulos G: Cryosurgery for lung cancer: clinical results and technical aspects. Technol Cancer Res Treat 2004;3:143-150.

108 Walsh DA, Maiwand MO, Nath AR, Lockwood P, Lloyd MH, Saab M: Bronchoscopic cryotherapy for advanced bronchial carcinoma. Thorax 1990;45; 509-513.

109 Sheski FD, Mathur PN: Cryotherapy, electrocautery and brachytherapy. Clin Chest Med 1999;20:123-138.

110 De Weerdt S, Noppen M, Remels L, Vanherreweghe R, Meysman M, Vincken W: Successful removal of a massive endobronchial blood clot by means of cryotherapy. J Bronchol 2005;12:1:23-24.

111 Cardona AF, Reveiz L, Ospina EG, Ospina V, Yepes A: Palliative endobronchial brachytherapy for non-small cell lung cancer. Cochrane Database Syst Rev 2008;16: CD004284.

112 Remy J, Voisin C, Dupuis C, et al: Traitement des hémoptysies par embolisation de la circulation systémique. Ann Radiol (Paris) $1974 ; 17: 5-16$

-113 Remy J, Arnaud A, Fardou H, et al: Treatment of hemoptysis by embolization of bronchial arteries. Radiology 1977;122:3337.

114 Swanson KL, Johnson M, Prakash UBS, McKusick MA, Andrews JC, Stanson AW: Bronchial artery embolization, experience with 54 patients. Chest 2002;121:789-795.

115 Cremaschi P, Nascimbene C, Vitulo P, et al: Therapeutic embolization of bronchial artery: a successful treatment in 209 cases of relapse hemoptysis. Angiology 1993;44: 295-299. 
116 Ramakantan R, Bandekar VG, Gandhi MS: Massive hemoptysis due to pulmonary tuberculosis: control with bronchial artery embolization. Radiology 1996;200:691694.

117 Tanaka N, Yamakado K, Murashima S, Takeda K, Matsumura K, Nakagawa T, Takano K, Ono M, Hattori T: Superselective bronchial artery embolization for hemoptysis with a coaxial microcatheter system. J Vasc Interv Radiol 1997;8:65-70.

118 Hayakawa K, Tanaka F, Torizuka T: Bronchial artery embolization for hemoptysis: immediate and long-term results. Cardiovasc Intervent Radiol 1992;15:154-159.

-119 Rabkin JE, Astafjev VI, Gothman LN, et al: Transcatheter embolization in the management of pulmonary hemorrhage. Radiology 1987;163:361-365

120 Wong ML, Szkup P, Hopley MJ: Percutaneous embolotherapy for life-threatening hemoptysis. Chest 2002;121:95-102.

- 121 Barben J, Robertson D, Olinsky A, Ditchfield M: Bronchial artery embolization for hemoptysis in young patients with cystic fibrosis. Radiology 2002;224:124-130.

122 White RI: Bronchial artery embolotherapy for control of acute hemoptysis. Chest 1999; 115:912-915.
123 Hsu AAL: Thoracic embolotherapy for lifethreatening haemoptysis: a pulmonologist's perspective. Respirology 2005; 10: 138-143.

124 Katoh O, Kishikawa T, Yamada H, et al: Recurrent bleeding after arterial emboliza tion in patients with hemoptysis. Chest 1990;97:541-546.

125 Remy J, Lemaitre L, Lafitte JJ, Vilain MO, Saint Michel J, Steenhouwer F: Massive hemoptysis of pulmonary arterial origin: diagnosis and treatment. AJR Am J Roentgenol 1984; 143:963-969.

126 Shin TB, Yoon SK, Lee KN, Choi JS, Kim YH, Sung CG, Kim YJ, Kim CW: The role of pulmonary CT angiography and selective pulmonary angiography in endovascular management of pulmonary artery pseudoaneurysms associated with infectious lung diseases. J Vasc Interv Radiol 2007; 18: 882-887.

127 Munk PL, Vellet AD, Rankin RN, Müller NL, Ahmad D: Intracavitary aspergilloma: transthoracic percutaneous injection of amphotericin gelatin solution. Radiology 1993;188:821-823.

128 Chen JC, Chang YL, Luh SP, Lee JM, Lee YC: Surgical treatment for pulmonary aspergilloma: a 28 year experience. Thorax 1997;52:810-813.

129 El Oakley R, Petrou M, Goldstraw P: Indications and outcome of surgery for pulmonary aspergilloma. Thorax 1997;52:813815
130 Haitjema TJ, Overtoom TT, Westermann CJ, Lammers JW: Embolisation of pulmonary arteriovenous malformations: results and follow-up in 32 patients. Thorax 1995; 50:719-723.

131 Gourin A, Garzon AA: Operative treatment of massive hemoptysis. Ann Thorac Surg 1974:52-60.

132 Yoo JH, Lee CT Shim YS, Chung JW, Ahn H, Kim KW: Aortobronchial fistula presenting as recurrent hemoptysis and successfully treated with an endovascular stent graft. Respiration 2001;68:537-539.

133 Pirrelli S, Bozzani A, Arici V, Odero A: Endovascular treatment of acute haemoptysis secondary to aortobronchial fistula. Eur J Vasc Endovasc Surg 2006;32:366-368.

134 Islam S, Williams DM, Teitelbaum DH: Aortobronchial fistula from invasive Aspergillus infection of the lung: an endovascular approach to repair. J Pediatr Surg 2005;40:E19-E22.

135 Wheatley GH 3rd, Nunez A, Preventza O, Ramaiah VG, Rodriguez-Lopez JA, Williams J, Olsen D, Diethrich EB: Have we gone too far? Endovascular stent-graft repair of aortobronchial fistulas. J Thorac Cardiovasc Surg 2007;133:1277-1285. 